\title{
A multi-analysis approach for space-time and economic evaluation of risks related with livestock diseases: the example of FMD in Peru.
}

\author{
Martínez-López, B. ${ }^{\text {abc* }}$, Ivorra, B. ${ }^{\text {d }}$, Fernández-Carrión, E. ${ }^{\text {, }}$ Perez, AM ${ }^{\mathrm{a}}$, Medel-Herrero, \\ A. ${ }^{\mathrm{e}}$, Sánchez-Vizcaíno, F. ${ }^{\mathrm{b}}$, Gortázar, $\mathrm{C}^{\mathrm{C}}{ }^{\mathrm{C}}$, Ramos AM. ${ }^{\mathrm{d}}$, Sánchez-Vizcaíno, JM. ${ }^{\mathrm{b}}$
}

${ }^{a}$ Center for Animal Disease Modeling and Surveillance, VM: Medicine and Epidemiology, UC Davis, California, USA.

${ }^{b}$ VISAVET. Veterinary School. Complutense University of Madrid. Av. Puerta de Hierro s/n. 28040, Spain.

'IREC (CSIC-UCLM-JCCM), Ronda de Toledo s/n; 13005, Ciudad Real, Spain.

${ }^{d}$ Applied Mathematics Department. Mathematics School. Complutense University of Madrid. Plaza de Ciencias 3, 28040, Madrid, Spain.

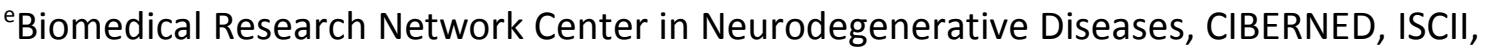
Madrid.

*Corresponding author: Beatriz Martínez-López.

Email: beamartinezlopez@ucdavis.edu; Tel: +1 5307520336.

\begin{abstract}
This study presents a multi-disciplinary decision-support tool, which integrates geostatistics, social network analysis (SNA), spatial-stochastic spread model, economic analysis and mapping/visualization capabilities for the evaluation of the sanitary and socio-economic impact of food animal diseases under diverse epidemiologic scenarios. We illustrate the applicability of this tool using foot-and-mouth disease (FMD) in Peru as an example. The approach consisted on a flexible, multistep process that may be easily adapted based on data availability. The first module ( $\mathrm{ml}$ ) uses a geo-statistical approach for the estimation (if needed) of the distribution and abundance of susceptible population (in the example here, cattle, swine, sheep, goats, and camelids) at farm-level in the region or country of interest (Peru). The second module (mII) applies SNA for evaluating the farm-to-farm contact patterns and for exploring the structure and frequency of between-farm animal movements as a proxy for potential disease introduction or spread. The third module (mIII) integrates ml-II outputs into a spatialstochastic model that simulates within- and between-farm FMD-transmission. The economic module $(\mathrm{mIV})$, connects outputs from $\mathrm{mI}-\mathrm{III}$ to provide an estimate of associated direct and indirect costs. A visualization module $(\mathrm{mV})$ is also implemented to graph and map the outputs of module I-IV. After 1000 simulated epidemics, the mean (95\% probability interval) number of outbreaks, infected animals, epidemic duration, and direct costs were 73 (1-1164), 2,152 (113,250), 63 days (0-442), and US\$1.2 million (1,072-9.5 million), respectively. Spread of disease was primarily local $(<4.5 \mathrm{~km})$, but geolocation and type of index farm strongly influenced the extent and spatial patterns of an epidemic. The approach is intended to support decisions in the last phase of the FMD eradication program in Peru, in particular to inform and support the implementation of risk-based surveillance and livestock insurance systems that may help to prevent and control potential FMD virus incursions into Peru.
\end{abstract}




\section{Introduction}

Livestock play a crucial role for the socio-economy of South American countries and certain diseases, such as foot-and-mouth disease (FMD), have had a severe impact on the livestock industry, limiting the trade of animals and animal products and impairing the economic development of the region (Romero et al., 1999; Naranjo and Cosivi, 2013). For this reason many countries, in collaboration with international organizations, have established regional or national projects to progressively control and finally eradicate FMD. Peru has currently achieved "FMD-free without vaccination" status in more than $98.3 \%$ of the country, the remaining $1.7 \%$ is "FMD-free with vaccination" and the country is pursuing FMD eradication by 2015 (FAO, 2013).

Peru is currently believed to be one of the world's fastest-growing economies and Peruvian products are exported worldwide, with a variety of partners that includes China, the United States, Canada, Japan, the European Union, and Chile (BBC, 2011; SIICEX, 2013). In such emerging economy, acquisition and maintenance of the "freestatus" for diseases, such as FMD, is vital to facilitate the development of the livestock sector and to sustain international trade of animals and animal products.

However, any future ban on FMD vaccination associated with eradication will bring a certain risk for Peru due to the potential for FMD re-introduction into a naïve population. Consequently, surveillance and control programs will need to be redesigned to account for this new epidemiological scenario (i.e. freedom from disease) with the ultimate goal of designing and implementing the most cost-effective measures to preserve FMD-free status. Implementation of a risk-based livestock insurance system may be a valuable tool for preventing, mitigating, and controlling potential FMD outbreaks, particularly in the scenario where there is limited or no economical compensation to farmers after an FMD outbreak. The application of livestock insurance systems may be beneficial for Peru in a number of aspects. On the one hand, it will contribute to the rapid notification of the disease (in case of reintroduction), because the farmer would receive compensation for the affected animals, which would allow the Animal Health Authorities to rapidly implement control measures and prevent further FMD spread. On the other hand, insurance is expected to play a role in FMD prevention by motivating producers to implement good practices in order to reduce the cost of the insurance premium and by establishing a set of minimum requirements and conditions producers must meet on both animal management and health status in order to obtain the right of compensation. Nevertheless, prerequisite for the design of risk-based surveillance systems or the implementation of livestock premiums, is detailed information and data on risk and economic metrics associated with alternative epidemiological scenarios (including, at least, best, most-likely, and worst-case scenarios) and the associated correspondent measures of uncertainty and variability. Such output would require the integration of a variety of tools, borrowing concepts and methods from diverse disciplines, such as spatial analysis, stochastic modelling, social analysis, and economics, into one single methodological framework. We failed to identify in the peer reviewed literature studies that provide such an integrated framework to prevent and control animal diseases in a real-case setting.

The multi-analysis decision-support system presented here was developed to: 1) quantitatively and stochastically assess the risk for potential FMD re-introduction 
into Peru (first component); and 2) quantify the FMD spread and economic impact associated with hypothetic FMD epidemics (second component). The paper here presents methods and results used for the latter component, which integrates a number of epidemiological tools that evaluate the sanitary and economic consequences of hypothetical FMD epidemics in the country. Ultimately, the multianalysis system presented here was developed to inform both: 1) Peruvian animal health authorities on the identification of risks and supporting risk-based surveillance and control programs; and 2) livestock insurance companies and stakeholders by providing a scientific basis for implementing livestock premiums to cover FMDassociated risks and mitigate the potential economic impacts of FMD re-introductions into Peru. This multi-analysis approach is flexible and scalable, and it may be readily adapted and implemented for evaluating FMD in other regions or countries or as a decision support tool for other food animal diseases.

\section{Material and methods}

\subsection{Data}

Data needed for conducting the multi-analysis approach is comprised of animal demographics and contact patterns, economic information (such as the annual value or market price of animals) and maps (depicting demographic and environmental features of the targeted region). Specific details about data requirements and data collected for this study are presented for each module (sections 2.2-2.6).

\subsection{Geo-statistical approach for the estimation of the distribution/abundance of susceptible populations at the farm-level in Peru.}

This first module was applied to estimate (as needed here) the spatial distribution and abundance of the susceptible population at farm-level in the country of study (i.e. Peru). No detailed (i.e. farm level) and updated (i.e. 2013) animal census and spatial distribution of farms was available to us. For that reason, and because animal demographics were believed to resemble that from the 1994 census (SENASA, personal com.), we used this first module to: 1) estimate the current (2013) number of FMD-susceptible animals (i.e. census) and farms in Peru, 2) geocode the farms per district, and 3) estimate the demographics at farm level (i.e. farm size, animal age and gender).

Specifically, we gathered information about the FMD susceptible livestock in Peru (i.e. cattle, pig, sheep, goat, alpaca, llama) at a district level (i.e. Peruvian lowest administrative unit) for the year 1994 from the third National Agricultural Census (CENAGRO, 1994). Data consisted of: 1) the number of farms per species; 2) the number of animals per species, gender and age, 3 ) farm size (i.e. total number of animals on farm); and 4) the number of pure breed animals on the farm for each of the 1,834 districts in Peru (mean, median and, 5 and 95 percentiles of district area in Peru is $70.26,20.72,1.94$ and $234.93 \mathrm{~km}^{2}$, respectively). 


\subsubsection{Estimation of the number of FMD susceptible animals and farms for 2013}

We used trend analysis based on linear regression models to estimate the FMD susceptible species per district for the year 2013 based on 1) the temporal evolution of the different FMD susceptible species available from 1994 to 2005 per department (Ministerio de Agricultura, 2013) and 2) the number of farms and animals per species, age and gender per district during 1994 (CENAGRO, 1994). Linear regression models were appropriate because a marked linear trend for most of the species and departments was estimated $\left(R^{2}\right.$ values $\left.=0.90-0.95\right)$. Regression models were fitted using the function Im of the library stats in R language ( $R$ Core Team, 2013).

Firstly, we used linear regression to fit the data from 1994 to 2005 to the linear formula:

$$
A_{t, s, k}=\alpha_{1994, s, k}+\beta_{s, k} *(t-1994)
$$

where $A_{t, s, k}$ is the number of FMD susceptible animals of species $s$ in department $k$ per year $t, \alpha_{1994, s, k}$ is the intercept, which approximately corresponded to the number of animals of species $s$ in department $k$ during year 1994), and $\beta_{s, k}$ is the slope, which represents the number of animals of species $s$ increasing/decreasing per year $t$ in the department $k$.

Then, assuming that all districts within each department were experiencing similar and proportional increases and decreases as that the ones observed at the departmental level we estimated the number of FMD susceptible animals of species $s$ in district $j$ of department $k$ for year $t\left(A_{t, s, j}\right)$ as follow:

$$
A_{t, s, j}=\alpha_{1994, s, j}+\frac{\beta_{s, k(j)}}{m_{k}} *(t-1994)
$$

where $\alpha_{1994, s, j}$ is the intercept (i.e. the number of FMD susceptible animals of species $s$ in district $j$ of department $k$ during 1994), $k(j)$ is the department where district $j$ is located, and $m_{k}$ is the number of districts in the department $k$. We used this formula to compute $A_{2013, s, j}$.

The number of farms of species $s$ in district $j$ during year $t, F_{t, s, j}$, was assumed to be proportional to the number of farms and similar in farm size and animal types of those observed in 1994 but for the corresponding number of animals in year $t$ and, then, $F_{t, s, j}$ was calculated as:

$$
F_{t, s, j}=\frac{A_{2013, s, j} * F_{1994, s, j}}{\alpha_{1994, s, j}}
$$

where $F_{1994, s, j}$ is the number of farms of species $s$ in district $j$ observed during 1994 (CENAGRO, 1994). We used this formula to compute $F_{2013, s, j}$.

2.2.2. Geocoding and estimation of farm demographics (i.e. farm size, and animals age and gender).

We generated random points on a polygon using the csr function of the library splancs (Rowlingson and Diggle, 1993), implemented in $\mathrm{R}$ language to produce the specific set of $n$ point locations per district corresponding to the number of farms estimated to exist per district during $2013\left(n=F_{2013, s, j}\right)$. As a result, each farm $i$ was assumed to have a specific set of latitude and longitude coordinates.

Because each farm $i$ of species $s$ in district $j$ was assumed to have the same farm size and proportion of animals by gender and age as the ones observed during 
1994 we estimated the number of animals of species $s$ gender $g$ and age $a$ at farm $i$ for year $t, A_{t, s, g, a, i}$, as follows:

$$
A_{t, s, g, a, i}=\frac{A_{2013, s, j}}{F_{2013, s, j}} * p_{1994, s, g, a}
$$

where $p_{1994, s, g, a}$ is the proportion of animals of species $s$, gender $g$ and age $a$ on farm observed during 1994 (Table 1). We used this formula to compute $A_{2013, s, g, a, i}$.

\subsection{Social network analysis for evaluation of farm-to-farm contact patterns}

The module of social network analysis ( $\mathrm{mll}$ ) was implemented to evaluate the patterns of direct contacts among farms and compute centrality measures for each farm.

Information about animal movements within Peru from farm-to-farm was based on the Domestic Transit Health Certificate (CSTI) data for 2011 and 2012 (although only data from 2011 was used here) and it was provided by the National Agrarian Health Service of Peru (SENASA, Ministry of Agriculture). Specifically, we obtained information about the origin, destination, day of movement, number of animals moved per species, purpose of movement (i.e. trade; fattening; exhibition; reproduction; consumption; slaughterhouse; other) owner-ID and driver-ID and truckID involved in the movement.

First, spatially explicit networks were constructed using premises as nodes and yearly (year graph) or monthly (monthly graphs) movements as edges. Movements to slaughterhouses were assumed to have a negligible risk for FMD spread and were not considered in the analysis. Second, we computed several standard statistics such as shipment size (i.e. number of animals shipped) and Euclidean distances per shipment, and SNA metrics such as node centrality measures (i.e. degree and closeness, Freeman, 1979). Briefly, degree centrality is a measure of the number of incoming (in-degree) or outgoing (out-degree) shipments that a farm has. Closeness centrality is an indicator of how closely connected a farm is from (in-closeness) or to (out-clonessnes) all other farms. These metrics are assumed to be proxies for potential introduction and/or spread of FMD into or out of a farm (Martínez-López et al., 2009). This module was developed and run in R-language using library igraph (Csardi and Nepusz, 2006).

\subsection{Spatial and stochastic model for the simulation of within- and between-farm disease transmission (Be-FAST)}

In module III, we adapted a previously described and validated model referred to as Be-FAST (Martínez-López et al., 2011; 2012; Ivorra et al., 2013) for the simulation of within- and between- farm transmission of FMD in Peru. Values of parameters that changed from those described in the original model are detailed in table 2.

We ran 1000 epidemics using different index farms (i.e. different farm type, trade patterns on farm, farm size, and farm geolocation) because we were specifically interested in evaluating the magnitude and duration of potential FMD epidemics under diverse epidemiologic conditions. We specifically defined four scenarios and run 250 epidemics for each one of them. In the first scenario, the index farm was randomly selected throughout Peru. In the second, index farms were selected from farms that had an out-degree>0 during 2011 (i.e. farms sending animals to other farms during 
2011). For the third scenario, the index farm was randomly selected among those farms located in the two ecological regions of Peru, coast and mountains (Figure 1), that have the highest farm density. Finally, in the fourth scenario, the index farm was randomly selected only from farms located in northern Peru (i.e. departments of Tumbes, Piura, Cajamarca, Lambayeque, Amazonas, Loreto, and San Martin), which includes the districts currently not recognized as free-without vaccination (i.e. high risk region). The index farms selected for starting the FMD epidemics per scenario are shown in Figure 1.

Model results were summarized using the mean and 95\% probability interval (PI) and include: the number of infected and quarantined farms and animals; the duration (in days) of the epidemic and of the quarantine; the risk of a farm becoming infected, defined as the number of times that a farm becomes infected considering all simulations; the between herd effective reproduction ratio, $R_{h}$, defined as the amount of secondary infections caused by one infected farm in a "not naïve" population (Anderson and May, 1991); the proportion of farms infected by direct contacts (i.e. animal movements), local spread, movements of people and of vehicles; the percentage of farms detected as infected by observation of clinical signs, active surveillance in the control and surveillance zones and tracing. We also computed the percentage of epidemics that resulted in a non-spread of the disease and that lasted more than 2 years (i.e. became endemic). This module was developed and run in MATLAB ${ }^{\circledR}$ (Ver.7.5.0.342 R2007b-The Math-Works Inc.) and model outputs were summarized using R language with library doBy (Højsgaard and Halekoh, 2013).

\subsection{Economic analysis: potential costs to be covered by livestock insurance systems.}

In this IV module, we were interested in quantifying the direct and indirect costs associated with potential FMD epidemics and that may be covered by livestock insurance. Specifically, we computed the direct costs associated with animal compensation (i.e. dead or slaughtered animals) and the indirect costs associated with the animals quarantine (i.e. depreciation of animal value and cost of feed). Direct and indirect costs were estimated per each scenario as a function of 1) the number of FMD-affected animals of species $s$ in each age-gender category (i.e. adult female, adult male, juveniles obtained from modules I and III output); 2) duration and number of farms (and animals) quarantine, obtained by outputs of module III; 3) animal market prices for each department of Peru and each animal category during 2013, obtained from module I output and an expert opinion survey (see below); and 4) costs associated with the quarantine of animals, which were assumed to be similar but slightly (25\%) smaller than the ones estimated for the livestock insurance systems in Spain (see for example: Ministerio de Agricultura, Alimentacion y Medio Ambiente, 2013): 7US\$ per week for adult cattle, 3US\$ per week for young cattle and adult pig; 2US\$ per week for adult sheep, goat, alpaca and llama; 1 US\$ per week for young sheep, goat, pig, alpaca, llama. Only farms quarantined between 3 and 17 weeks were assumed to be eligible for compensation. Specifically, the minimum, most likely, and maximum animal and animal products market price in Peru was collected using an Excel based questionnaire (in Spanish language) that was distributed to experts from different departments in Peru. The (translated) tables of the questionnaire are presented in the supplementary material. Pert distributions were created using those 
minimum, most likely and maximum values and integrated into the analysis using the library mc2d (Pouillot et al., 2013) (Figure 2).

Productivity effects (morbidity and mortality) and control costs, among others, were not quantified because it was out of the scope this analysis.

\subsection{Mapping tool: spatial visualization of outputs from modules I-IV}

This module consists of the integration of graphical and mapping capabilities to explore outputs of modules I-IV. We produce boxplots, histograms, epidemic curves and raster and vector maps to facilitate the temporal and spatial representation and interpretations of results for decision makers. For raster maps we specifically used quartic kernel function with a correction for edge effects implemented in the kernel2d function (library splancs, Rowlingson and Diggle, 1993). Fisher-Jenks algorithm (Fisher, 1958) was used for determining data categorization (library classInt, Bivand et al., 2013b). Maps of the administrative regions of Peru at the first (department), second (province), and third (district) levels of administrative organization were gathered from the Ministry of Environment of Peru (Ministerio del Ambiente, 2013).

This module was developed and run in R-language using also the libraries maps (Becker and Wilks, 2013), maptools (Bivand et al., 2013a), mapproj (Mcllroy, 2013), sp (Pebesma et al., 2013), RColorBrewer (Neuwirth, 2011).

\subsection{Sensitivity analysis and validation}

An extensive sensitivity and validation analysis showing the impact of changes in the input data and in model parameters have on the results of the Be-FAST model were performed and presented in literature (Martinez-Lopez et al., 2012; Ivorra, et al., 2013).

Because we used estimated spatial farm locations for the model, we wanted to address the impact that changes in farm coordinates may have on model outputs, so we ran additional $(n=100)$ simulations with perturbation of $10 \mathrm{~km}$ in the geolocation of farms within the district and statistically compared the results with the baseline scenario described in section 2.4. using the Wilcoxon tests implemented in R language (library stats, Hollander and Wolfe, 1999).

For validation purposes, we visually compared the estimated magnitude, duration and spatial distribution of FMD epidemics with those recorded in previous FMD epidemics in Peru.

\section{Results}

\subsection{Spatial distribution and demographics of susceptible population at farm-level in} Peru.

The estimated total number of FMD susceptible animals and farms for Peru in 2013 was $27,671,887$ and 1,986,750, respectively. The estimated number of animals and farms per farm size and type of animal is shown in table 3.

High density areas corresponded to the coast and mountain ecological regions (Figure 3). Half of all farms $(49.3 \%)$ in Peru were estimated to be small size $(<8$ 
animals), whereas $43.3 \%$ and $7.4 \%$ were classified as medium (9-38 animals) and large (>38 animals) sized, respectively (Figure 3 ).

\subsection{Farm-to-farm contact patterns.}

The network of farm-to-farm animal movements in Peru during 2011 included 12,068 nodes (farms) and 16,650 edges (movements). The mean, median and (95\% PI) number of animals shipped by movement was 17, 13 and $(1,70)$, respectively, although there were big differences in the shipment size by species (Table 4). The number of animals moved per month by species is shown in Figure 4 . Most $(78.2 \%)$ of the movements originated from medium to large cattle farms and most (84.6\%) of the shipments were of cattle (table 4 and Figure 5). Farms with high (i.e. above the mean) values of out-degree and out-closeness centrality were mostly found in north and south part of Peru (Figure 6).

\subsection{Within- and between-farm FMD transmission}

The overall mean (95\% PI) number of infected farms and animals after 1000 model simulations were $73(1,1,164)$ and $2,152(0,13,250)$, respectively (Table 5). The mean $(95 \% \mathrm{PI})$ time (in days) to detection and duration of the epidemic were $11(1,38)$ and $64(0,442)$, respectively. Spread of disease was primarily local with the mean $(95 \% \mathrm{PI})$ number of infected districts equal to $4(1,16)$ and the mean $(95 \% \mathrm{PI})$ distance from the source of infection to the infected farm of $4.5 \mathrm{~km}(0.5,10.0)$.

The percentage of farms (and percentage of animals) infected corresponding to small, medium and large farm sizes was $39.6 \%$ (8.4\%), $54.5 \%(62.4 \%)$, and $5.9 \%$ (29.2\%), respectively.

The mean $(95 \% \mathrm{PI})$ risk and $R_{\mathrm{h}}$ values were $1.32(1,4)$ and $2.79(1,11)$, respectively. Most (99.46\%) of the infections were due to local spread, whereas $55.5 \%$ of detections were associated with active surveillance in the control zone. Up to $8.5 \%$ of the initially infected index cases were not spreading further the disease. A total of $6 \%$ of the epidemics lasted more than 2 years (i.e. maximum simulated period).

The highest magnitude and duration of FMD simulated epidemics were observed for scenario 2 (random index farm among those with out-degree $>0$ ), whereas scenario 4 (random index farm among those located in norther Peru) had the lowest values (Table 5).

The highest risk of a farm becoming FMD infected was concentrated in the coast and mountains ecological areas for all scenarios (Figure 7). Largest epidemics were observed when mixed farms were selected as index cases with a mean (95\% PI) number of infected farms of $224(1,678)$. This figure for index cases being cattle, sheep, goat, alpaca and llama farms was 192 (1, 1993), 107 (1, 605), 48 (1, 589), 98 (1, 923), $73(1,289), 79(3,227)$, respectively.

\subsection{Economic analysis}

The overall mean (95\% $\mathrm{PI}$ ) direct costs associated with dead or slaughtered animals in a FMD epidemic in Peru was US\$1.19 million (1,072-9.5 million) (Table 5). Lambayeque (mean= US\$2.9million), Puno (mean= US\$2.6 million), Lima (mean= 
US\$1.9 million) and Cusco (mean= US\$1.8 million) were the departments concentrating the highest direct costs per epidemic, whereas Loreto (mean= US\$3,934) and Ucayali (mean $=$ US\$25,527) were the ones with the lowest direct costs per epidemic (Figure 8). The highest direct costs per epidemic were associated with mixed and cattle farms and with farms of medium or large farm sizes (Figure 8).

The mean $(95 \% \mathrm{PI})$ indirect costs associated with quarantine of animals in a FMD epidemic in Peru was US\$120,700 $(0,735,907)$. The highest cost of quarantine was associated with cattle and sheep farms with a mean $(95 \% \mathrm{PI})$ of US\$ 4,344 $(0$, $33,092)$ and US\$2,786 $(0,18,730)$ costs per farm per epidemic, respectively.

The scenario 2 (random index farm among those with out-degree>0) was the one showing the highest direct and indirect costs (Table 5).

\subsection{Sensitivity analysis and validation}

Random perturbations of $10 \mathrm{~km}$ of the farm geolocations were not substantially modifying the magnitude (i.e. number of infected farms and animals) and duration of the simulated FMD epidemics in Peru (Wilcoxon tests were no significant, $p$ value $>0.05$ ).

Estimated magnitude, duration and spatial location of FMD epidemics in Peru were very similar to those observed in historical epidemics in the country and described by Estrada et al., (2004) and Valderrama (2010) (Figure 9 and 10). Values of the herd reproduction ratio, $R_{h}$, described by Estrada et al. (2004) (referred here as the between herd effective reproduction ratio, $\left.R_{h}\right)$ for the day $2\left(R_{h}=5.3\right)$ and $25\left(R_{h}=1.31\right)$ were also in the range of those obtained here for the total number of simulations $\left(R_{h}=2.79\right.$ with 95\% PI $\left.(1,11)\right)$ and for the different scenarios (Table 5).

\section{Discussion}

This study is the first to provide detailed quantitative estimates of the risk of FMD spread, including a sanitary and economic impact analysis of potential FMD epidemics in Peru, for the scenario of re-introduction after eradication. These results were generated using a multi-analysis approach that integrates geo-statistical $(\mathrm{ml})$, social network analyses ( $\mathrm{mll})$, a spatial and stochastic within- and between- farm spread model (mIII), an economic analysis ( $\mathrm{mlV}$ ) and mapping and visualization capabilities $(\mathrm{mV})$. These modules were specifically adapted to Peruvian epidemiologic conditions, legislation (Gobierno de Peru, 2004) and data availability and can be easily adapted if additional or new information becomes available (e.g. updated farm census or farm-to-farm movements). Results provided in this study will be useful to inform the development of risk-based surveillance systems and the implementation of livestock insurance systems to better prevent and control future FMD epidemics in Peru.

Results revealed that future FMD epidemics in Peru are expected to have a relatively small magnitude (73 infected farms, 2,152 infected animals), duration (64 days), and economic impact (1.2 million US\$), with most (99\%) of the premises infected by local spread (Table 5), which is in agreement with the transmission patterns and self-limiting nature of FMD spread reported in previous studies (Estrada et al., 2004, Valderrama, 2010). Surprisingly, $8.5 \%$ of index cases did not even result in further FMD spread. This may be explained, at least in part, by the combination of an 
isolated location (i.e. no farms around), small farm sizes and the scarce trade patterns (i.e. no outgoing movements) of many farms in Peru, particularly, those in Jungle and mountain regions. However, the model also shows that FMD epidemics under certain epidemiological conditions (i.e. index farms located in high density areas, with high number of outgoing shipments, large farm size, and mixed species on farm) may lead to wider spread epidemics (Table 5 and Figure 7); note that around 6\% of the epidemics may persist for more than two years (and hence FMD may become endemic again), which highlights the importance of implementing appropriate measures to prevent and rapidly control potential FMD-reintroductions. One preventive measure may be the implementation of risk-based surveillance in farms or areas identified to be at "high risk" for FMD re-introduction and spread or the use of livestock insurance systems, that may not only assist in the mitigation of FMD economic costs but will also promote the rapid notification of infected farms. For example, in light of the results here mixed or cattle farms, particularly those with medium or large farm size (Figure 5 and 8) and large values of out-degree or out-closeness (Figure 6) and located in areas identified to be at high risk of becoming FMD infected (Figure 7) should be target for the implementation of risk-based surveillance strategies. Similarly, the risk and direct and indirect costs estimated considering the demographics and species raised on farm, farm size, trade patterns and geolocation (Figures 5, 6 and 8) of the farm should provide foundations for computing adequate livestock premiums adapted for each type of farm in Peru.

A sound epidemiological base is essential for conducting realistic risk and economic analyses (Rushton et al., 2008; Rich and Perry, 2011). For that reason, considerable effort has been exerted to ensure these analytic methods: 1 ) realistically estimate and approximate the on farm demographics (i.e. age, gender), spatial distribution, abundance and the farm-to-farm contact patterns of the FMD susceptible population in Peru (module I and II) and; 2 ) as accurately as possible simulate FMD transmission using a stochastic within- and between- farm spread model (module III). A cross disciplinary team with epidemiologists, infectious disease experts, mathematical modellers and a sociologist was used for such purpose. Expertise from Peruvian livestock specialists was also gathered though expert opinion surveys. We believe that the estimates obtained here are compatible with historic data and biologically sound, in light of the comparison with the number, location and $R_{h}$ estimates of historical outbreaks (Figure 9 and 10), and that offer detailed measurements and uncertainties on estimates, which are prerequisite for supporting the design and implementation of risk-based surveillance and livestock insurance systems. However, there are a number of limitations and assumptions that need to be considered when interpreting the results presented. First, the number of farms and animals were estimated based on trend analysis from historic information at a district and department level. Second, the specific farm location within a district was assumed to be random. The use of actual farm demographics and coordinates may increase the accuracy of the predictions; unfortunately, such information was not available to us and, to the best of our knowledge, it is not currently available in Peru. Moreover, model estimates were robust to changes in farm coordinates, which suggests that the outputs presented here were consistent. Third, a number of assumptions were made for both the Be-FAST model and the economic analysis due to the lack of information, mostly for parameters related with alpacas and llamas. For example, alpacas and 
llamas were considered to have the same within-farm transmission parameter than sheep or goat (i.e. worst case scenario), which may lead to an overestimation of the FMD spread, particularly in epidemics involving llama and alpaca herds (i.e. less than $1 \%$ of the total number of simulated epidemics). However, the impact of such overestimation of FMD spread is expected to be very low as camelids make up a very small proportion (only 1.1\%) of the population at risk. We also assumed that vehicles transporting alpacas and llamas are $50 \%$ less likely to spread the disease than vehicles transporting other FMD susceptible animals. These assumptions were based on the much lower susceptibility and transmissibility reported for llamas and alpacas compared with other livestock species in previous studies (Lubroth et al., 1990; Sutmoller et al., 2003). Other assumption was that the potential FMD local spread was similar to the one reported by Sanson et al. (2006) for the 2001 FMD epidemic in UK because no information about probability of local spread was available for Peru. Note that by assuming this we did not account for the dense vegetation and particular orographic characteristics in the jungle and mountain regions of Peru, respectively. These natural barriers are certainly very difficult to account for and to incorporate in simulation models. As a result, local spread is likely to be overweighed here, producing an overestimation of the FMD spread, particularly, in the mountainous and selvatic regions of Peru (e.g. clustered pattern in Figure 7). Note also that our economic analysis was restricted to the estimation of the direct costs due to slaughter or dead of animals and the indirect costs due to quarantine of animals, as those were the most important estimates needed for the design of the livestock insurance systems. A natural extension of the economic analysis presented here (module IV) will be the incorporation of a more extensive socio-economic analysis that assesses the microand macro-economic impacts of potential FMD re-introductions at a farm, livestock sector and national level. Despite all the assumptions, we believe that a considerable effort has been made to provide a dynamic, realistic and complete framework in which assumptions (and code) are clearly presented and traced (i.e. transparent, not a blackbox) and that epidemiologic and economic estimates are a good representation of the real world the model tries to simplify. Model assumptions may also be easily improved if better values for the parameters become available.

In conclusion, this study provides detailed quantitative estimates on both the risk and economic costs of potential FMD epidemics in Peru, with the ultimate goal of informing decisions regarding risk-based surveillance and livestock insurance systems implementation. The approach presented here reflects a new generation of multianalysis systems that may be easily updated if more information becomes available or re-run for answering specific questions (what if scenarios) of different stakeholders. We believe that this integrated and almost-real time decision support tools will be very useful to better prevent and control livestock diseases.

\section{Acknowledgements}

This work has been funded by the technical collaboration agreement between UCM and ENESA as part of the FAO Regional Project for the Progressive Control Pathway for Foot-andMouth Disease (GCP/RLA/178/SPA and GTFS/RLA/172/ITA) and the Spanish National Project (MTM2011-22658). Authors would like to acknowledge SENASA (Ministry of Agriculture of Peru) and the ENESA-Agroseguro working groups for the provision of data and valuable discussions/comments. 


\section{References}

Anderson, R.M., May, R.M., 1991. Infectious diseases of humans: dynamics and control, $2^{\text {nd }}$ Edition. Oxford University Press.

BBC, 2011. Peru country profile. Available at: http://news.bbc.co.uk/2/hi/americas/country profiles/1224656.stm

Becker, R.A., Wilks, A.R., 2013. maps: draw Geographical Maps. $R$ version by Ray Brownrigg. Available at: $\underline{\text { http://cran.r- }}$ project.org/web/packages/maps/index.html

Bivand, R., Lewin-Koh, N., Pebesma, E., Archer, E. et al. 2013a. maptools: tools for reading and handling spatial objects. Available at: http://cran.rproject.org/web/packages/maptools/index.html

Bivand, R., Ono, H., Dunlap, R., Stigler, M., 2013b. classInt: Choose univariate class intervals. Available at: http://cran.rproject.org/web/packages/class/nt/index.html

Burrows, R., 1968. Excretion of foot-and-mouth disease virus prior to the development of lesions. Vet. Rec., 82, 387-388.

CENAGRO, 1994. III Censo Nacional Agropecuario 1994 [III National Agricultural Census]. National Institute of Statistics and Informatics of Peru. Available at: http://iinei.inei.gob.pe/iinei/cenagro1994/. Last accessed: Feb. 8, 2013

Csardi, G., Nepusz, T., 2006. The igraph software package for complex network research, InterJournal, Complex Systems 1695. Available at: http://igraph.sf.net

Estrada, C., Perez, A., Turmond, M., 2004. Herd reproduction ratio and time-space analysis of a foot-and-mouth disease epidemic in Peru in 2004. Transboundary and Emerging Diseases, 55, 284-292.

FAO, 2013. News: FAO reconoce a Perú esfuerzos para vencer la fiebre aftosa [FAO recognizes efforts to defeat FMD in Peru]. Available at: http://www.rlc.fao.org/es/prensa/noticias/fao-reconoce-a-peru-esfuerzospara-vencer-la-fiebre-aftosa/ . Last access: August 19, 2013.

Fisher, W. D., 1958. On grouping for maximum homogeneity. Journal of the American Statistical Association, 53, 789-798

Freeman, L.C., 1979. Centrality in Social Networks I: Conceptual Clarification. Social Networks, 1, 215-239.

Gobierno de Peru, 2004. Reglamento para la Prevención y Erradicación de la Fiebre Aftosa [Regulations for the Prevention and Eradication of foot-and-mouth disease]. Decreto supremo 042-2004-AG. Available at: http://www.senasa.gob.pe/RepositorioAPS/0/0/JER/ERR FIE AFT/1178.pdf

Højsgaard, S., Halekoh, U., 2013. doBy: Groupwise summary statistics, general linear contrasts, population means (least-squares-means), and other utilities. Available at: http://cran.r-project.org/web/packages/doBy/index.html

Hollander, M., Wolfe, D.A., 1999. Nonparametric Statistical Methods. New York: John Wiley \& Sons. $2^{\text {nd }}$ edition.

Ivorra, B., Martínez-López, B., Sánchez-Vizcaíno, J.M., Ramos, A.M., 2013. Mathematical formulation and validation of the Be-FAST model for Classical Swine Fever Virus spread between and within farms. Ann Oper Res, DOI 10.1007/s10479-012-1257-4. 
Lubroth, J., Yedloutschnig, R.J., Culhane, V.K., Mikiciuk, P.E., 1990. Foot-and-mouth disease virus in the Ilama (Lama glama): diagnosis, transmission, and susceptibility. J Vet Diagn Invest. 2, 197-203.

Martínez-López, B., Perez, A.M., Sánchez-Vizcaíno, J.M., 2009. Social Network Analysis. Review of General Concepts and Use in Preventive Veterinary Medicine. Transboundary and Emerging Diseases. 56, 109-120

Martínez-López, B., Ivorra, B., Ramos, A.M., Sánchez-Vizcaíno, J.M. 2011. A novel spatial and stochastic model to evaluate the within- and between-farm transmission of classical swine fever virus. I General concepts and description of the model. Vet. Microb., 147, 300-309.

Martínez-López, B., Ivorra, B., Ramos, A.M., Sánchez-Vizcaíno, J.M. 2012. A novel spatial and stochastic model to evaluate the within and between farm transmission of classical swine fever virus: II Validation of the model. Vet. Microb., 155, 21-32

Mcllroy, D., 2013. mapproj: Map Projections. Packaged for $R$ by Brownrigg $R$. and Minka, T.P., Available at: http://cran.rproject.org/web/packages/mapproj/index.html

McLaws, M., Ribble, C., Stephen, C, McNab, B., Romero Barrios, P., 2007. Reporting of suspect cases of foot-and-mouth-disease during the 2001 epidemic in the UK, and the herd sensitivity and herd specificity of clinical diagnosis. Prev Vet Med, 78, 12-23.

Ministerio de Agricultura, 2013. Capítulo 7 Estadística Pecuaria. Ministerio de Agricultura- Dirección General de Información Agraria- Dirección de Estadística. Perú.

Ministerio de Agricultura, Alimentacion y Medio Ambiente, 2013. Orden $A A A / 2895 / 2012$, por la que se definen las explotaciones, animales y grupos asegurables, las condiciones técnicas mínimas de explotación, el ámbito de aplicación, el periodo de garantía y los precios y fechas de suscripción en relación con el seguro de explotación de ganado vacuno de alta valoración genética, comprendido en el Plan Anual 2013 de Seguros Agrarios Combinados. Available

at: http://www.boe.es/boe/dias/2013/01/12/pdfs/BOE-A-2013-377.pdf

Ministerio del Ambiente, 2013. Geoservidor [Geoserver]. Available at: http://geoservidor.minam.gob.pe/intro/. Last access: March 3, 2013.

Naranjo, J., Cosivi, O., 2013. Elimination of foot-and-mouth disease in South America: lessons and challenges. Philos Trans R Soc Lond B Biol Sci. 368: 20120381.

Neuwirth, E., 2011. RColorBrewer: ColorBrewer palettes. Available at: http://cran.rproject.org/web/packages/RColorBrewer/index.html

Orsel, K., Bouma, A., Dekker, A., Stegeman, J.A., de Jong, M.C.M., 2009. Foot and mouth disease virus transmission during the incubation period of the disease in piglets, lambs, calves, and dairy cows. Prev Vet Med, 158-163.

Orsel, K., Dekker, A., Bouma, A., Stegeman, J.A., de Jong, M.C.M, 2007. Quantification of foot and mouth disease virus excretion and transmission within groups of lambs with and without vaccination. Vaccine, 2673-2679.

Pebesma, E., Bivand, R., Rowlingson, B., Gomez-Rubio, V., 2013. sp: classes and methods for spatial data. Available at: http://cran.rproject.org/web/packages/sp/index.html 
Pouillot, R., Delignette-Muller, M.L., Denis, J-B., 2013. mc2d: tools for two-dimensional Monte-Carlo simulations. Available at: http://cran.rproject.org/web/packages/mc2d/index.html

$R$ Core Team, 2013. $R$ : A language and environment for statistical computing. $R$ Foundation for Statistical Computing, Vienna, Austria. URL http://www.Rproject.org/

Rich, K.M., Perry, B.D., 2011. The economic and poverty impacts of animal diseases in developing countries: New roles, new demands for economics and epidemiology. Prev Vet Med, 101, 133-147.

Romero, J.R., Villamil, L.C., Pinto, J.A., 1999. Impacto económico de enfermedades en sistemas productivos en Sudamérica: estudios de caso [Economic impact of diseases on production systems in South America: case studies]. Rev. Sci. Tech. Off. Int. Epiz, 18, 498-511.

Rowlingson, B. and Diggle, P., 1993. splancs: spatial point pattern analysis code in SPlus. Computers and Geosciences, 19, 627-655; the original sources can be accessed at: http://www. maths.lancs.ac.uk/ rowlings/Splancs/

Rushton, J., 2008. Economic aspects of foot and mouth disease in Bolivia. Rev Sci Tech., 27, 759-769.

Sanson, R.L., Stevenson, M.A. and Moles-Benfell, N., 2006. Quantifying local spread probabilities for foot-and-mouth disease. Proceedings of the 11th Symposium of the International Society for Veterinary Epidemiology and Economics. Cairns, Australia, 6-11 August 2006.

SIICEX, 2013. Informe de las Exportaciones Peruanas por Sector - Septiembre 2013 [Report of Peruvian Exports by Sector - September 2013]. Peruvian Ministry of Foreign Trade and Tourism. In Spanish. Available at: http://www.siicex.gob.pe/siicex/documentosportal/1071282036rad05630.pdf

Sutmoller, P., Barteling, S.S., Olascoaga, R.C., Sumption, K.J., 2003. Control and eradication of foot-and-mouth disease. Virus Res., 91, 101-144

Valderrama, W., 2010. Evaluación económica y epidemiológica en programas de salud animal: el caso de fiebre aftosa en el Perú [Economic and epidemiological assessment of animal health programs: the case of FMD in Peru]. Master Thesis. 
Table 1. Proportion of animals of species $s$ by gender $g$ and age $a$ during 1994, $p_{1994, s, g, a}$, in each type of farm (i.e. cattle, sheep/goat, pig, alpaca/llama or mixed).

\begin{tabular}{|c|c|c|c|c|c|c|c|c|c|c|}
\hline \multirow[t]{2}{*}{ Animal type } & \multicolumn{2}{|c|}{ Cattle $e^{(1)}$} & \multicolumn{2}{|c|}{ Sheep/goat ${ }^{(1)}$} & \multicolumn{2}{|c|}{ Pig $^{(1)}$} & \multicolumn{2}{|c|}{ Alpaca/llama ${ }^{(2)}$} & \multicolumn{2}{|c|}{ Mixed $^{(3)}$} \\
\hline & mean & sd & mean & sd & mean & sd & mean & sd & mean & sd \\
\hline Adult Male & 0.15 & 0.04 & 0.17 & 0.05 & 0.20 & 0.10 & 0.17 & 0.05 & 0.17 & 0.06 \\
\hline Adult Female & 0.44 & 0.03 & 0.59 & 0.03 & 0.33 & 0.09 & 0.59 & 0.03 & 0.45 & 0.05 \\
\hline Young animals $(<3 \mathrm{~m})$ & 0.41 & 0.07 & 0.25 & 0.08 & 0.47 & 0.10 & 0.25 & 0.08 & 0.38 & 0.09 \\
\hline
\end{tabular}

$\mathrm{m}=$ months; $\mathrm{sd}=$ standard deviation

(1) Computed based on CENAGRO 1994

(2) Assumed to be equal to sheep/goat due to lack of information.

(3) Assumed to be an average of the proportion of animals observed for cattle, sheep/goat, and pig farms due to lack of information. 
Table 2. Assumptions and parameters used for the spatial and stochastic within- and between- spread model (Be-FAST) used for the simulation of FMD in Peru.

\begin{tabular}{|c|c|}
\hline Parameter & Value \\
\hline Within-farm transmission parameter ${ }^{(1)(2)}$ & $\begin{array}{l}\text { C: Beta }=0.125 ; \text { P: Beta }=0.150 ; \text { SG: } \\
\text { Beta }=0.105 ; \text { AL: Beta }=0.075 ; \mathrm{M}: \\
\text { Beta }=0.105\end{array}$ \\
\hline Number of pig movements from farm $h$ to farm $k$ at day $t^{(3)(4)}$ & Poisson $[\mathrm{M}(\mathrm{t})]^{*} \mathrm{~m}_{\mathrm{hk}} / \mathrm{MT}$ \\
\hline $\begin{array}{l}\text { Number of pigs moved during a simulated movement from farm } h \text { to } \\
\text { farm } k \text { at day } \mathrm{t}^{(3)(4)}\end{array}$ & $\mathrm{n}_{\mathrm{hk}} * \mathrm{~N}_{\mathrm{h}}(\mathrm{t}) / \mathrm{N}_{\mathrm{h}}(0)^{\mathrm{b}}$ \\
\hline $\begin{array}{l}\text { Probability of infection by animal contacts due to a movement from } \\
\text { farm } h \text { to farm } k \text { at day } t\end{array}$ & $\begin{array}{l}\text { Poisson }[\mathrm{M}(\mathrm{t})]^{*} \mathrm{~m}_{\mathrm{hk}} / \\
\mathrm{MT} \mathrm{T}_{\mathrm{hk}}{ }^{*} \mid \mathrm{p}_{\mathrm{h}}(\mathrm{t}) / \mathrm{N}_{\mathrm{h}}(0)^{\mathrm{c}}\end{array}$ \\
\hline $\begin{array}{l}\text { Probability of infection by contact with vehicles transporting } \\
\text { infected animals }{ }^{(2)}\end{array}$ & $\begin{array}{l}\text { C,P,SG,M: Bernoulli [0.3] } \\
\text { AL: Bernoulli [0.15] }\end{array}$ \\
\hline Maximum number of visits that a vehicle can do per day ${ }^{(2)}$ & 4 \\
\hline $\begin{array}{l}\text { Number of contacts with vehicles transporting products per farm at } \\
\text { day } t^{(2)}\end{array}$ & Poisson [0.1] \\
\hline $\begin{array}{l}\text { Probability of infection by contacts with vehicles transporting } \\
\text { products }{ }^{(2)}\end{array}$ & Bernoulli [0.027] \\
\hline Maximum number of visits that a person can do per day ${ }^{(2)}$ & 3 \\
\hline Number of contacts with people per farm at day $\mathrm{t}^{(2)}$ & Poisson [0.2] \\
\hline Probability of infection by contact with people ${ }^{(2)}$ & Bernoulli [0.021] \\
\hline Probability of infection by local spread at day $t^{(5)(2)}$ & $\begin{array}{l}0.0629[0-<1 \mathrm{~km}] ; 0.0447[1-<2 \mathrm{~km}] \\
0.0303[2-<3 \mathrm{~km}] ; 0.0231[3-<4 \mathrm{~km}] ; \\
0.0144[4-<5 \mathrm{~km}] ; 0.0101[5-<6 \mathrm{~km}] ; \\
0.0050[6-<7 \mathrm{~km}] ; 0.0049[7-<8 \mathrm{~km}] ; \\
0.0040[8-<9 \mathrm{~km}] ; 0.0037[9-<10 \mathrm{~km}] ; \\
0\left[>10 \mathrm{~km}{ }^{*} \mathrm{Ip}_{\mathrm{h}(\mathrm{t})} / \mathrm{N}_{\mathrm{h}}(\mathrm{t})\right.\end{array}$ \\
\hline Latent period (transition from infected to infectious state) ${ }^{(6)(2)}$ & Poisson [7] \\
\hline Transition from infectious to clinical signs state ${ }^{(6)(2)}$ & Poisson [2] \\
\hline $\begin{array}{l}\text { Probability of farm detection based on clinical signs at day t before } \\
\text { detection of the index case }\end{array}$ & Bernoulli [0.047] \\
\hline $\begin{array}{l}\text { Probability of farm detection based on clinical signs at day t outside } \\
\text { the control and surveillance zones }\end{array}$ & Bernoulli [0.0575] \\
\hline $\begin{array}{l}\text { Probability of farm detection based on clinical signs at day } t \text { in the } \\
\text { control zone }(2)\end{array}$ & Bernoulli $\left[0.98\left(\frac{I p_{h}(t)}{N_{h}(t)}\right)\right]$ \\
\hline
\end{tabular}




\begin{tabular}{|c|c|}
\hline $\begin{array}{l}\text { Probability of farm detection based on clinical signs at day } t \text { in the } \\
\text { surveillance zone }\end{array}$ & Bernoulli $\left[0.95\left(\frac{I p_{h}(t)}{N_{h}(t)}\right)\right]$ \\
\hline Probability of farm detection based on serological test ${ }^{(7)(2)}$ & Bernoulli [0.95] \\
\hline Radius (duration) of the protection zone ${ }^{(2)}$ & $3 \mathrm{~km}$ (min of 45 days) \\
\hline Radius (duration) of the surveillance zone ${ }^{(2)}$ & $10 \mathrm{~km}$ (min of 40 days) \\
\hline $\begin{array}{l}\text { Probability of restriction of animal movements on the detected as } \\
\text { infected farm }{ }^{(2)}\end{array}$ & Bernoulli [0.99] \\
\hline $\begin{array}{l}\text { Probability of restriction of vehicle movements on the detected as } \\
\text { infected farm }\end{array}$ & Bernoulli [0.95] \\
\hline $\begin{array}{l}\text { Probability of restriction of people movements on the detected as } \\
\text { infected farm }\end{array}$ & Bernoulli $[0.80]$ \\
\hline $\begin{array}{l}\text { Probability of restriction of animal movements within the control } \\
\text { and surveillance zone }{ }^{(2)}\end{array}$ & Bernoulli [0.7] \\
\hline $\begin{array}{l}\text { Probability of restriction of vehicle movements within the control } \\
\text { and surveillance zone }{ }^{(2)}\end{array}$ & Bernoulli [0.90] \\
\hline $\begin{array}{l}\text { Probability of restriction of people movements within the control } \\
\text { and surveillance zone }{ }^{(2)}\end{array}$ & Bernoulli [0.70] \\
\hline $\begin{array}{l}\text { Duration of the restriction of movements outside the control and } \\
\text { surveillance zones } \\
{ }^{(2)}\end{array}$ & 90 days \\
\hline \multirow{2}{*}{$\begin{array}{l}\text { Probability of restriction of movements outside the control and } \\
\text { surveillance zones }{ }^{(2)}\end{array}$} & C,P,SG,M: Bernoulli [0.3] \\
\hline & AL: Bernoulli [0.1] \\
\hline Probability to depopulate a detected as infected farm ${ }^{(2)}$ & 1 \\
\hline Maximum number of farms to be depopulated at day $t^{(2)}$ & Poisson [20] \\
\hline Time to repopulation of a depopulated farm ${ }^{(2)}$ & Poisson [90] \\
\hline \multirow[t]{2}{*}{ Probability of tracing an animal movement ${ }^{(2)}$} & C,P,SG,M: Bernoulli [0.8] \\
\hline & AL: Bernoulli [0.4] \\
\hline \multirow[t]{2}{*}{ Probability of tracing a vehicle movement ${ }^{(2)}$} & C,P,SG,M: Bernoulli [0.8] \\
\hline & AL: Bernoulli [0.4] \\
\hline \multirow[t]{2}{*}{ Probability of tracing a vehicle transporting products ${ }^{(2)}$} & C,P,SG,M: Bernoulli [0.7] \\
\hline & AL: Bernoulli [0.35] \\
\hline Probability of tracing a people movement ${ }^{(2)}$ & $\mathrm{C}, \mathrm{P}, \mathrm{SG}, \mathrm{M}$ : Bernoulli [0.6] \\
\hline
\end{tabular}




\footnotetext{
${ }^{(1)}$ Orsel et al., 2007 ; ${ }^{(2)}$ Expert opinion; ${ }^{(3)}$ CSTI of Peru $2011 ;{ }^{(4)}$ Martínez-López et al., 2011; ${ }^{(5)}$ Sanson et al $2006 ;{ }^{(6)}$ Burrows, 1968 and Orsel et al., $2009 ;{ }^{(7)}$ McLaws et al., 2007.

Type of farm is coded as follows: $\mathrm{C}=$ cattle; $\mathrm{P}=$ pig; $\mathrm{SG}=$ sheep and goat; $\mathrm{AL}=$ alpaca and llama; $M=$ mixed; other notation used: $M(t)=$ number of movements occurring during 2011 at day $t ; m_{\mathrm{hk}}=$ number of movements from farm $h$ to farm $k$ during 2011; MT = total number of movements in Peru during 2011; $n_{h k}=$ number of animals moved between farm $h$ and $k$ during $2011 ; N_{h(t)}=$ number of animals on farm $h$ at time $t ; \mathrm{lp}_{\mathrm{h}(\mathrm{t})}$ $=$ number of infected animals on farm $h$ at time $t$.
} 
Table 3. Estimated number (and percentage) of farms and animals by species raised on farm (i.e. cattle, sheep, goat, pig, alpaca, llama, mix), type of farm (i.e. small $=<8$ animals; medium=9-38 animals; and large $=>38$ animals), and type of animal (i.e.breeding male and female and juvenile animals) used to perform the FMD simulations.

\begin{tabular}{|c|c|c|c|c|c|c|c|c|}
\hline & Cattle & heep & Goat & Pig & Alpaca & Llama & Mix & Total \\
\hline $\begin{array}{r}\text { \# of small farms } \\
\%\end{array}$ & & & & & & & $\begin{array}{c}89 \\
(0.004)\end{array}$ & \\
\hline $\begin{array}{r}\text { \# of medium farms } \\
\%\end{array}$ & $\begin{array}{r}285,72 \\
(14.3\end{array}$ & $\begin{array}{r}144,681 \\
(7.28)\end{array}$ & $\begin{array}{l}9,830 \\
(0.49)\end{array}$ & $\begin{array}{r}27,652 \\
(1.39)\end{array}$ & $\begin{array}{l}1,480 \\
(0.07)\end{array}$ & $\begin{array}{l}9,154 \\
(0.46)\end{array}$ & $\begin{array}{l}382,078 \\
(19.23)\end{array}$ & $\begin{array}{l}860,604 \\
(43.30)\end{array}$ \\
\hline $\begin{array}{r}\text { \# of large farms } \\
\%\end{array}$ & $\begin{array}{l}36,638 \\
(1.84)\end{array}$ & $\begin{array}{l}8,588 \\
(0.43)\end{array}$ & $\begin{array}{l}501 \\
(0.03)\end{array}$ & $\begin{array}{l}1,304 \\
(0.07)\end{array}$ & & $\begin{array}{c}11 \\
(0.001)\end{array}$ & $\begin{array}{l}98,793 \\
(4.97)\end{array}$ & \\
\hline $\begin{array}{r}\text { Total \# of farms } \\
\%\end{array}$ & $\begin{array}{r}465,217 \\
(23.42)\end{array}$ & $\begin{array}{r}432,269 \\
(21.76)\end{array}$ & $\begin{array}{r}97,521 \\
(4.91)\end{array}$ & $\begin{array}{r}409,026 \\
(20.59)\end{array}$ & $\begin{array}{r}70,887 \\
(3.57)\end{array}$ & $\begin{array}{r}30,870 \\
(1.55)\end{array}$ & $\begin{array}{r}480,960 \\
(24.21)\end{array}$ & $\begin{array}{c}1,986,750 \\
(100)\end{array}$ \\
\hline $\begin{array}{r}\text { ing) } \\
\text { nals } \\
\%\end{array}$ & $\begin{array}{r}527,738 \\
(1.91)\end{array}$ & $\begin{array}{r}407,761 \\
(1.47)\end{array}$ & $\begin{array}{l}38,649 \\
(0.14)\end{array}$ & $\begin{array}{l}90,314 \\
(0.33)\end{array}$ & $\begin{array}{l}5,037 \\
(0.02)\end{array}$ & $\begin{array}{r}21,358 \\
(0.08)\end{array}$ & $\begin{array}{r}1,419,582 \\
(5.13)\end{array}$ & $\begin{array}{c}2,510,439 \\
(9.07)\end{array}$ \\
\hline $\begin{array}{r}\text { \# of female } \\
\text { (breeding) animals } \\
\%\end{array}$ & $\begin{array}{r}3,175,022 \\
(11.47)\end{array}$ & $\begin{array}{r}2,678,052 \\
(9.68)\end{array}$ & $\begin{array}{r}325,710 \\
(1.18)\end{array}$ & $\begin{array}{r}340,156 \\
(1.23)\end{array}$ & $\begin{array}{r}54,274 \\
(0.2)\end{array}$ & $\begin{array}{r}153,592 \\
(0.56)\end{array}$ & $\begin{array}{r}7,486,462 \\
(27.05)\end{array}$ & $\begin{array}{c}14,213,268 \\
(51.36)\end{array}$ \\
\hline $\begin{array}{r}\text { \# of juvenile } \\
\text { (<3months) animals } \\
\%\end{array}$ & $\begin{array}{r}2,929,940 \\
(10.59)\end{array}$ & $\begin{array}{r}1,061,536 \\
(3.84)\end{array}$ & $\begin{array}{r}96,374 \\
(0.35)\end{array}$ & $\begin{array}{r}450,658 \\
(1.63)\end{array}$ & $\begin{array}{r}12,928 \\
(0.05)\end{array}$ & $\begin{array}{r}57,504 \\
(0.21)\end{array}$ & $\begin{array}{r}6,339,240 \\
(22.91)\end{array}$ & $\begin{array}{c}10,948,180 \\
(39.57)\end{array}$ \\
\hline $\begin{array}{r}\text { Total \# of animals } \\
\%\end{array}$ & $\begin{array}{c}6,632,700 \\
(23.97)\end{array}$ & $\begin{array}{c}4,147,349 \\
(14.99)\end{array}$ & $\begin{array}{c}460,733 \\
(1.66)\end{array}$ & $\begin{array}{c}881,128 \\
(3.18)\end{array}$ & $\begin{array}{l}72,239 \\
(0.26)\end{array}$ & $\begin{array}{c}232,454 \\
(0.84)\end{array}$ & $\begin{array}{c}15,245,284 \\
(55.09)\end{array}$ & $\begin{array}{c}27,671,887 \\
(100)\end{array}$ \\
\hline
\end{tabular}

Farm size

$\overline{\mathrm{X}}$; median;

$14 ; 11 ; \quad 10 ; 7$

$5 ; 2$;

$2 ; 0$;

$1 ; 0 ;$

$8 ; 2$

$32 ; 24$

$14 ; 9$

$\#=\begin{array}{ccc}(95 \% \mathrm{PI}) & (0,54) \quad(2,35) \quad(0,16)\end{array}$

$(0,27)$

$(0,7)$

$(0,29)$

$(11,88)$

$(0,62)$ 
Table 4. Descriptive statistics of the farm-to-farm movement characteristics in Peru during 2011.

${ }^{(1)}$ Camelid includes alpaca and Ilama; $\bar{x}=$ mean; $\mathrm{PI}=$ probability interval

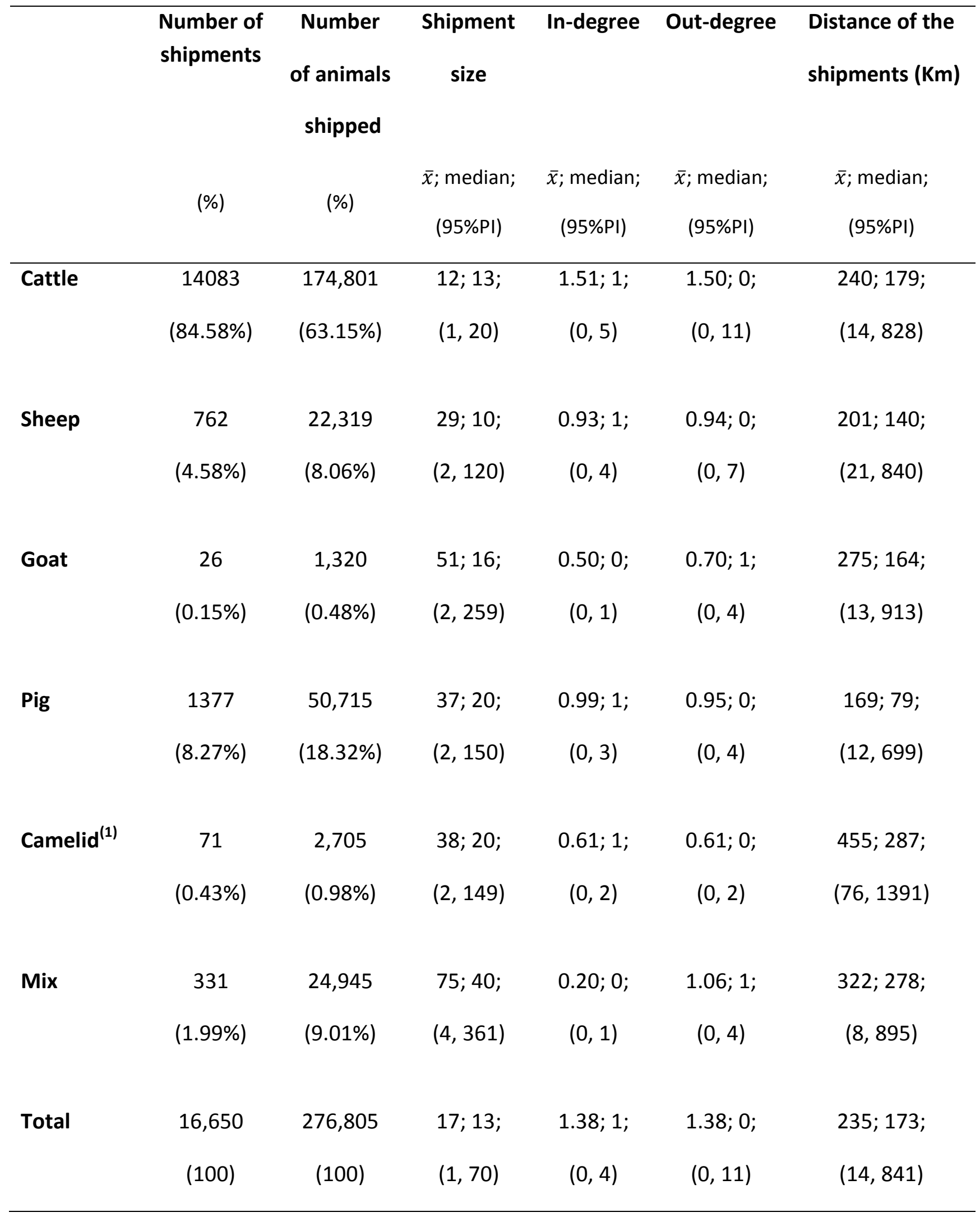


Table 5. Magnitude, duration and economic costs of the FMD simulated epidemics within Peru when considering the overall 1000 epidemics (Total) and each of the scenarios: random selection of the index farm (sce1), random index farm among those with outgoing shipments (out-degree $>0$ ) (sce2), random index farm among those located in coast or mountain (sce3) and random index farm among those located in the North of Peru (sce4).

\begin{tabular}{|c|c|c|c|c|c|}
\hline & sce1 $(n=250)$ & sce2 $(n=250)$ & sce3 $(n=250)$ & sce4 $(n=250)$ & Total $(n=1000)$ \\
\hline & Mean (95\% PI) & Mean (95\% PI) & Mean (95\% PI) & Mean (95\% PI) & Mean (95\% PI) \\
\hline Number of infected farms & $48(0,378)$ & $62(0,494)$ & $34(0,333)$ & $5(0,40)$ & $73(0,1164)$ \\
\hline $\begin{array}{l}\text { Number of infected } \\
\text { animals }\end{array}$ & $2631(0,13149)$ & $3310(9,23577)$ & $2502(0,10793)$ & $153(0,1158)$ & $2,152(0,13250)$ \\
\hline $\begin{array}{l}\text { Number of infected } \\
\text { districts }\end{array}$ & $2(1,8)$ & $4(1,21)$ & $2(1,6)$ & $3(1,11)$ & $4(1,16)$ \\
\hline Duration of the epidemic & $69(0,500)$ & $91(0,726)$ & $57(0,199)$ & $35(0,189)$ & $64(0,442)$ \\
\hline $\begin{array}{l}\text { Number of quarantined } \\
\text { farms in the control zone } \\
(<3 \mathrm{~km})\end{array}$ & $\begin{array}{c}63,570(332 \\
209,994)\end{array}$ & $\begin{array}{l}55,250(390 \\
294,523)\end{array}$ & $\begin{array}{l}8,504(8 \\
110,933)\end{array}$ & $\begin{array}{c}40,490(11 \\
98,701)\end{array}$ & $\begin{array}{c}44,330(135 \\
248,894)\end{array}$ \\
\hline $\begin{array}{l}\text { Number of quarantined } \\
\text { farms in the surveillance } \\
\text { zone }(<10 \mathrm{~km})\end{array}$ & $\begin{array}{c}76,410(52 \\
732,384)\end{array}$ & $\begin{array}{l}83,810(47 \\
1,063,775)\end{array}$ & $\begin{array}{c}15,460(114, \\
124,044)\end{array}$ & $\begin{array}{c}47,170(153 \\
243,857)\end{array}$ & $\begin{array}{c}50,900(11 \\
766,742)\end{array}$ \\
\hline $\begin{array}{l}\text { Number of quarantined } \\
\text { farms as suspected }\end{array}$ & $208(1,1853)$ & $225(1,2729)$ & $33(1,328)$ & $63(1,418)$ & $129(1,1,486)$ \\
\hline Duration of quarantine & $115(18,717)$ & $120(14,730)$ & $98(11,364)$ & $77(15,219)$ & $103(13,718)$ \\
\hline Time to detection & $9(1,31)$ & $10(1,37)$ & $10(1,24)$ & $15(4,49)$ & $11(1,38)$ \\
\hline Risk & $1.09(1,2)$ & $1.83(1,9)$ & $1.10(1,2)$ & $1.11(1,2)$ & $1.32(1,4)$ \\
\hline $\mathrm{R}_{\mathrm{h}}$ & $2.61(1,10)$ & $3.33(1,14)$ & $2.44(1,9)$ & $1.98(1,6)$ & $2.79(1,11)$ \\
\hline $\begin{array}{l}\text { Direct costs (due to animal } \\
\text { slaughter) in US\$ }\end{array}$ & $\begin{array}{l}1.36 \text { mill }(972, \\
8.2 \mathrm{mill})\end{array}$ & $\begin{array}{l}2.09 \text { mill }(7,051, \\
15.5 \text { mill })\end{array}$ & $\begin{array}{l}1.22 \text { mill }(652 \\
5.1 \mathrm{mill})\end{array}$ & $\begin{array}{c}102,052(178 \\
963,846)\end{array}$ & $\begin{array}{l}\text { 1.19mill }(1,072, \\
9.5 \mathrm{mill})\end{array}$ \\
\hline \multirow[t]{2}{*}{$\begin{array}{l}\text { Indirect costs (due to } \\
\text { quarantine) in US\$ }\end{array}$} & $\begin{array}{c}180,000(0 \\
794,444)\end{array}$ & $\begin{array}{c}149,000(0 \\
674,460)\end{array}$ & $\begin{array}{l}42,850(0 \\
219,237)\end{array}$ & $\begin{array}{c}122,200(0 \\
603,714)\end{array}$ & $\begin{array}{c}120,700(0 \\
735,907)\end{array}$ \\
\hline & $\%$ & $\%$ & $\%$ & $\%$ & $\%$ \\
\hline $\begin{array}{l}\% \text { of infection by } \\
\text { movement of animals }\end{array}$ & 0.01 & 0.21 & 0 & 0.02 & 0.09 \\
\hline $\begin{array}{l}\text { \% of infection by local } \\
\text { spread }\end{array}$ & 99.62 & 99.34 & 99.54 & 98.9 & 99.46 \\
\hline $\begin{array}{l}\% \text { of infection by } \\
\text { movement of people }\end{array}$ & 0.23 & 0.21 & 0.33 & 0.69 & 0.27 \\
\hline $\begin{array}{l}\% \text { of infection by vehicles } \\
\text { transporting products }\end{array}$ & 0.13 & 0.12 & 0.13 & 0.39 & 0.13 \\
\hline \multirow{2}{*}{$\begin{array}{l}\% \text { of infection by vehicles } \\
\text { transporting animals }\end{array}$} & 0.01 & 0.12 & 0 & 0 & 0.05 \\
\hline & $\%$ & $\%$ & $\%$ & $\%$ & $\%$ \\
\hline $\begin{array}{l}\% \text { of detection by clinical } \\
\text { signs }\end{array}$ & 47.7 & 21.2 & 40.2 & 8.15 & 33.8 \\
\hline $\begin{array}{l}\% \text { of detection by active } \\
\text { surveillance in the control } \\
\text { zone }\end{array}$ & 43.62 & 67.67 & 48.38 & 78.33 & 55.5 \\
\hline $\begin{array}{l}\% \text { of detection by active } \\
\text { surveillance in the } \\
\text { surveillance zone }\end{array}$ & 4.08 & 4.11 & 4.96 & 13.31 & 4.57 \\
\hline$\%$ of detection by tracing & 0.007 & 0.1 & 0 & 0 & 0.04 \\
\hline \multirow[t]{2}{*}{$\%$ of non detected farms* } & 4.59 & 6.92 & 6.46 & 0.21 & 6.09 \\
\hline & $\%$ & $\%$ & $\%$ & $\%$ & $\%$ \\
\hline $\begin{array}{l}\% \text { of epidemics lasting } \\
\text { more than } 2 \text { years }\end{array}$ & 4.55 & 6.97 & 6.43 & 0.2 & 6.07 \\
\hline
\end{tabular}


spreading further than the index case

*These farms were involved in epidemics lasting more than 2 years (i.e. simulation was stopped). 
Figure 1. Ecological regions of Peru: coast (blue), mountains (orange), jungle (green) and location of the 1000 index cases for the different scenarios: random selection of the index farm (sce1, $n=250$ ), random index farm among those with outgoing shipments (out-degree $>0$ ) (sce2, $n=250)$, random index farm among those located in coast or mountain (sce3, $n=250$ ) and random index farm among those located in the North of Peru (sce4, $n=250)$.
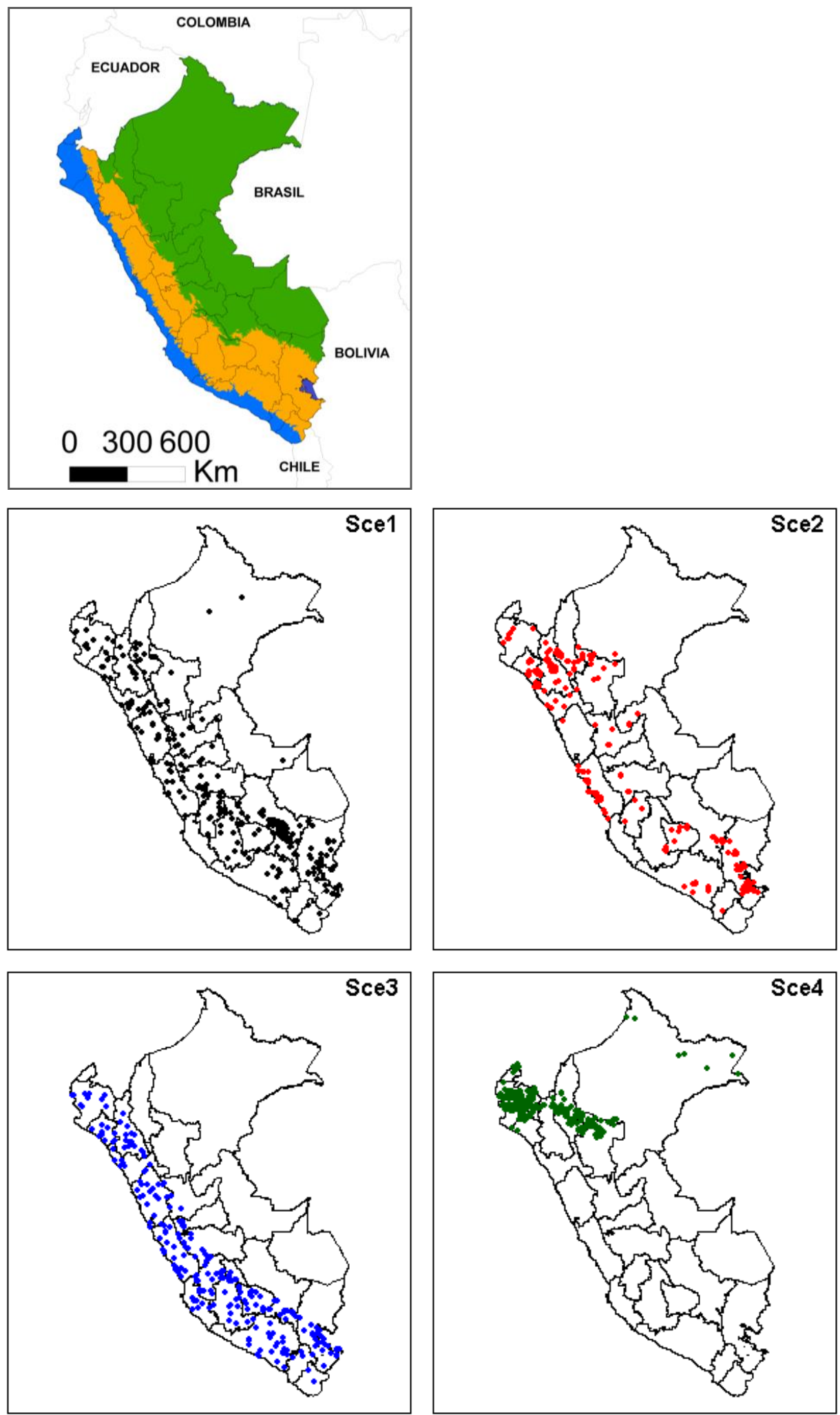
Figure 2. Example of pert distributions used for the 2013 value (US\$) of juvenile, female and male breeding cattle in the department of Huanuco (above) and Loreto (below) of Peru.
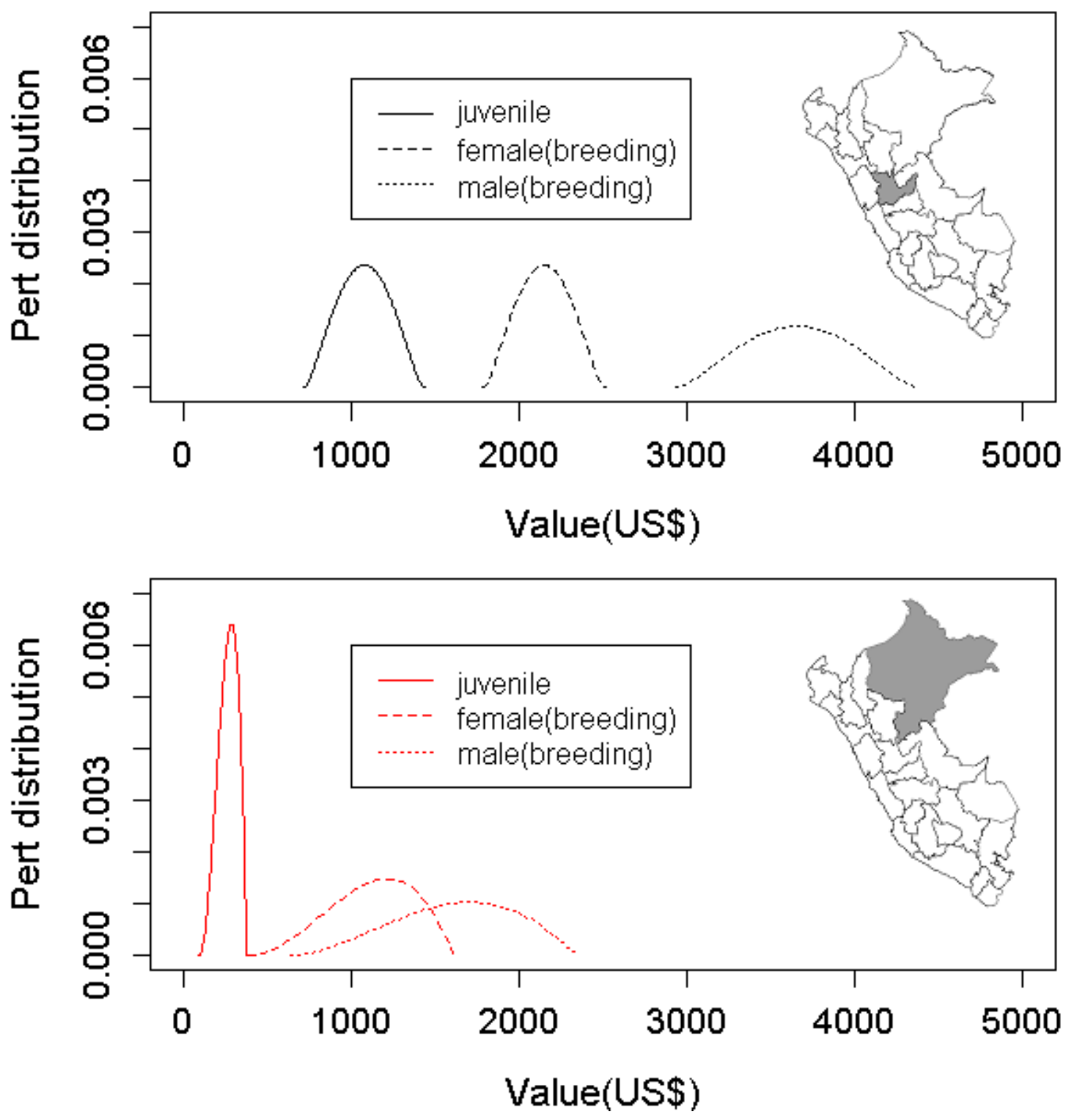
Figure 3. Estimated farm density per $\mathrm{km}^{2}$ by type of farm (i.e. cattle, sheep, goat, pig, alpaca, llama and mix) and in total in Peru during 2013. The graph is showing the estimated proportion of farms by farm size. Quartic kernel function with a correction for edge effects is used for plotting the maps. Fisher-Jenks algorithm was used to select the categories for the maps.

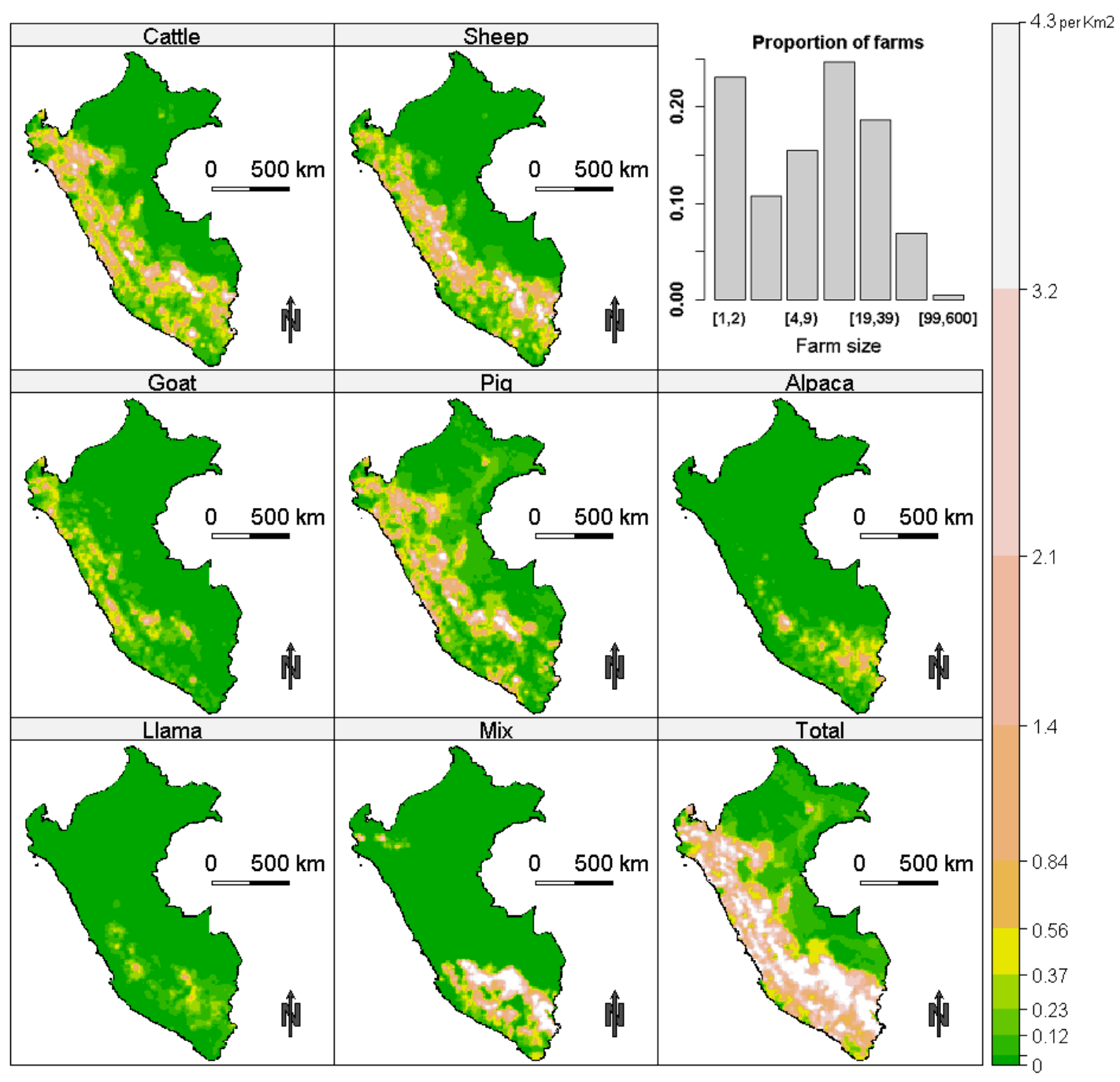


Figure 4. Number of animals moved per month by species in Peru: (a) cattle, (b) sheep, (c) goat, (d) pig, (e) camelid (i.e. alpaca and llama) and (f) mix.
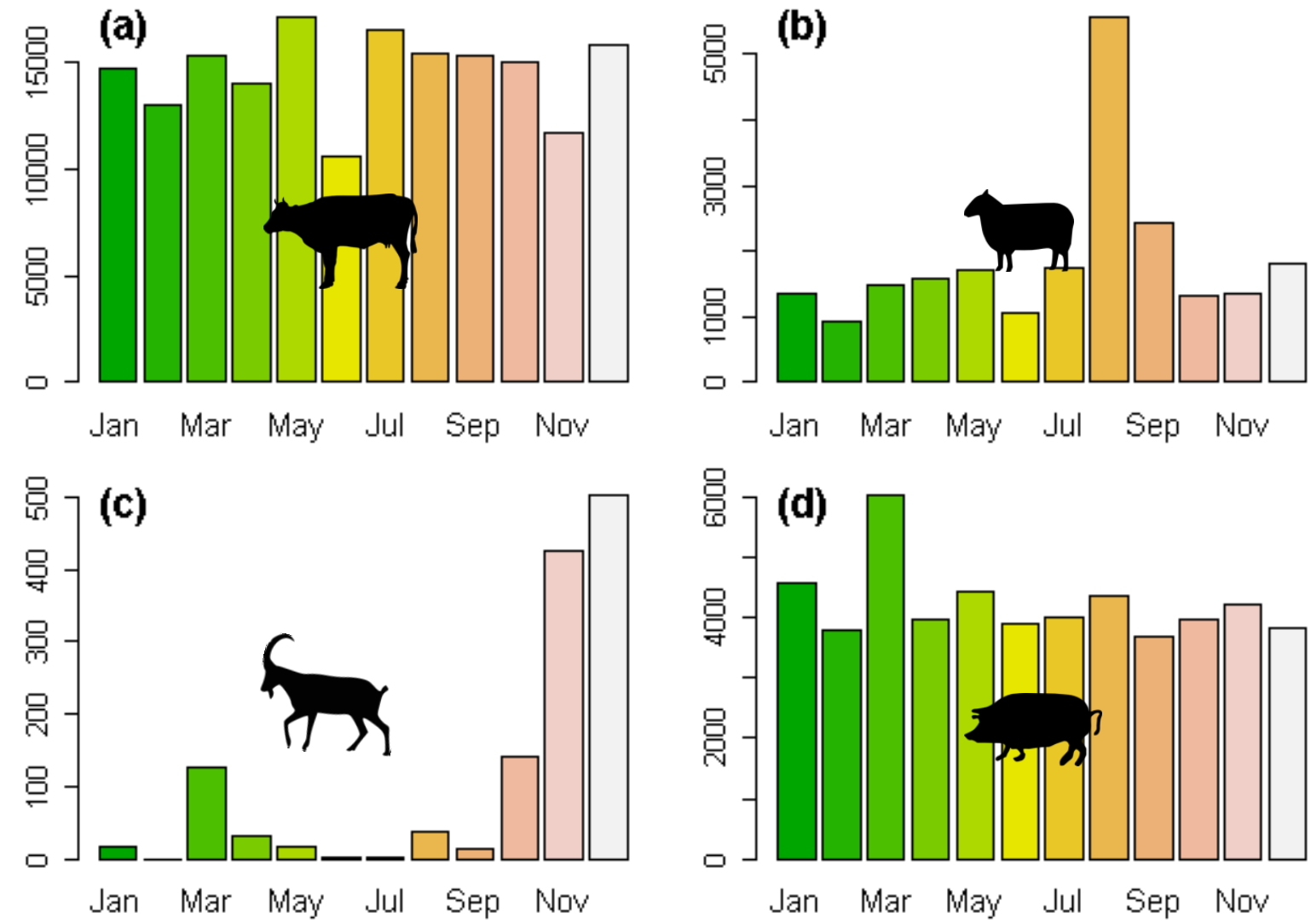

(e)
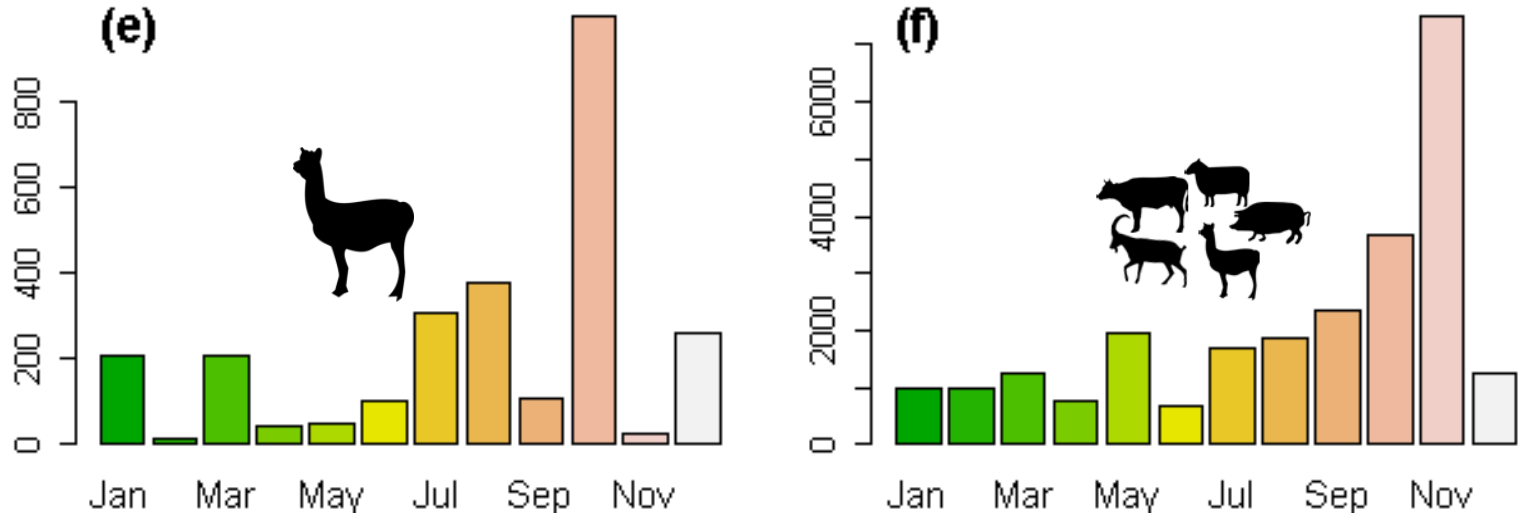
Figure 5. Spatial distribution of the farm-to-farm contact network during 2011 in Peru by farm size (a) and (b) species on farm.
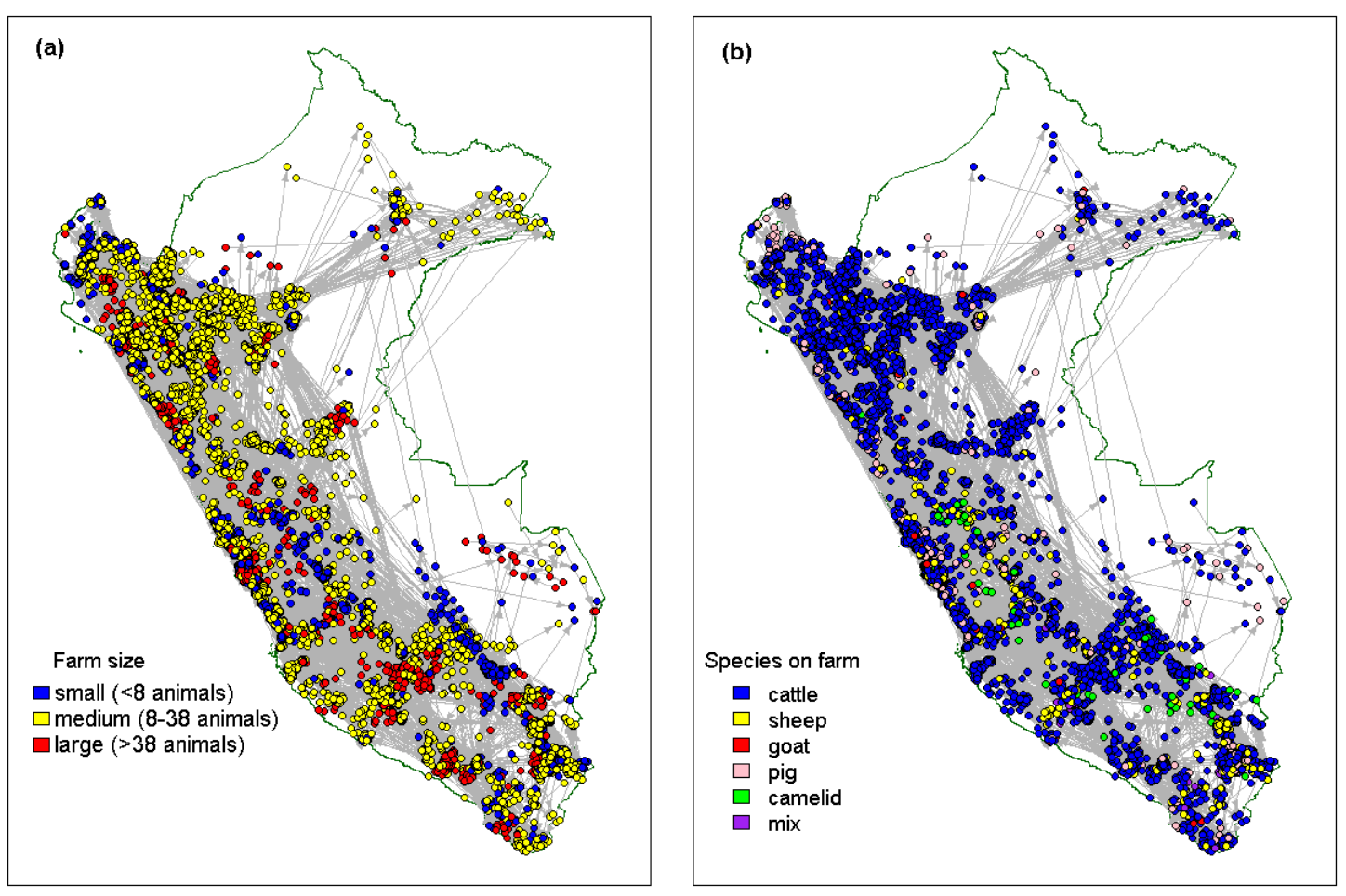
Figure 6. Spatial distribution of the centrality measures (a) normalized in-degree, (b) normalized out-degree, (c) in-closeness, (d) out-closeness for the 2011 farm-to-farm contact network in Peru. The mean has been used as cut off.
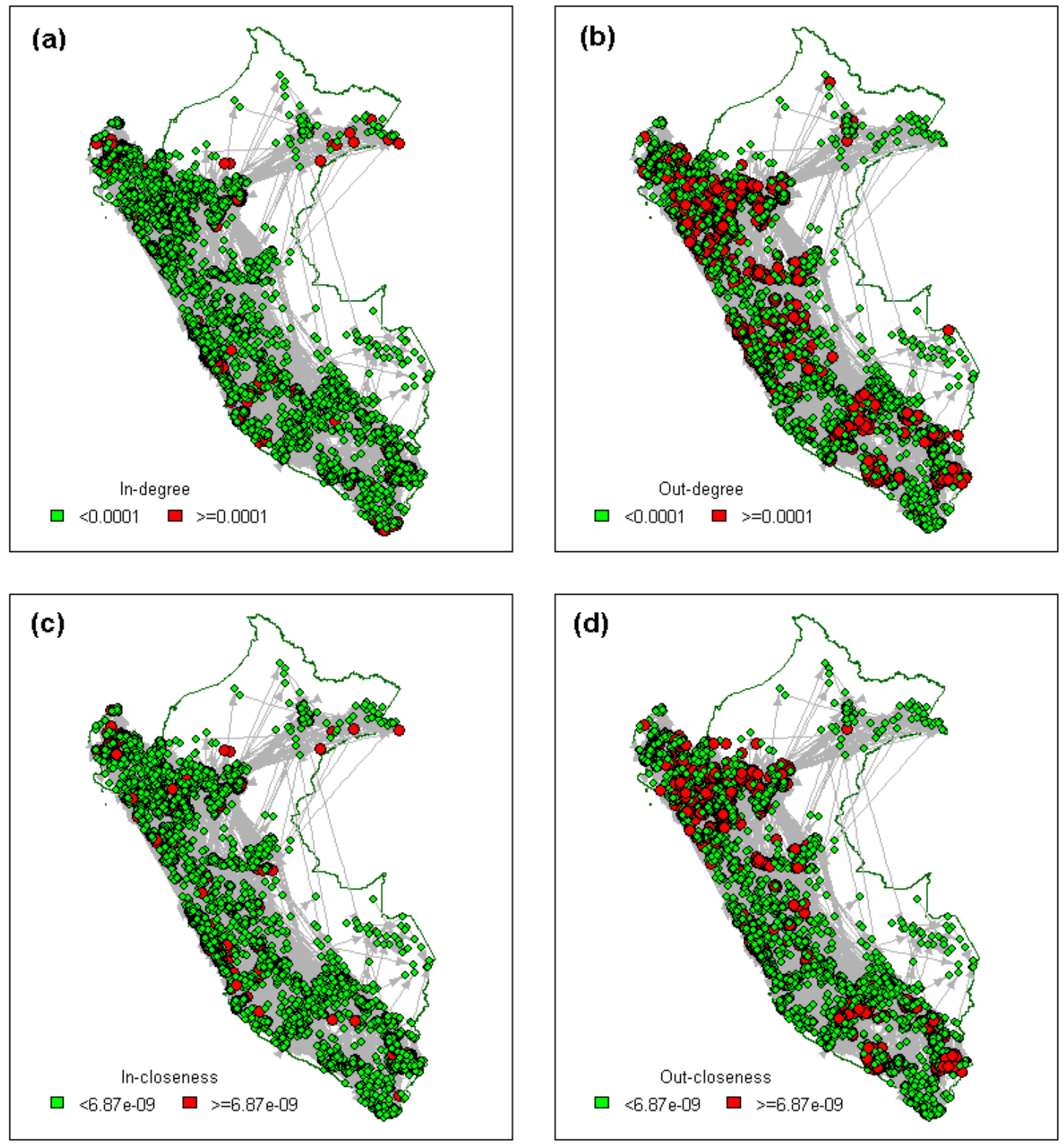
Figure 7. Risk maps of the potential FMD spread in the scenario with random selection of the index farm (sce1), random index farm among those with outgoing shipments (out-degree $>0$ ) (sce2), random index farm among those located in coast or mountain (sce3) and random index farm among those located in the North of Peru (sce4) and when considering the total number of simulations (total). Epidemic curve (with indication of the mean day of epidemic duration) for the total number of simulations is shown in the graph. Quartic kernel function with a correction for edge effects is used for plotting the maps. Fisher-Jenks algorithm was used to select the categories for the maps.

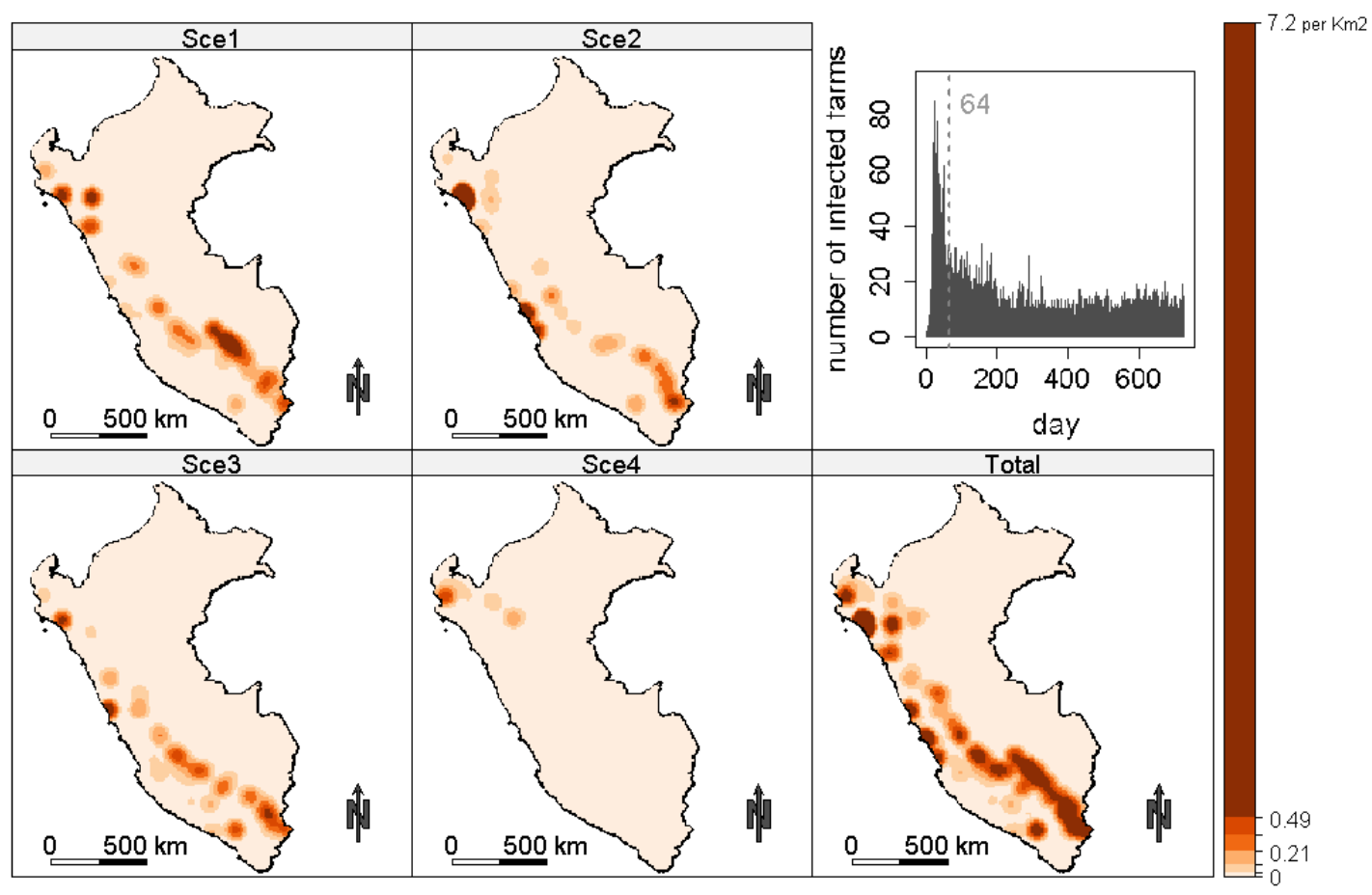


Figure 8. Boxplots (a, b, c, d) and map (e) of the estimated direct costs (\$US) associated with an FMD epidemic in Peru by farm type ( $a$, zoom in $c)$, farm size (b, zoom in d) and department (e). Boxes limits of the boxplots correspond to $1^{\text {st }}$ and $3^{\text {rd }}$ quartile, the whiskers represent the 1.5 times the interquartile range (IQR), and the median is represented by a bold line in the box. Department labels for the map are:

LA=Lambayeque; PU=Puno; Lima=LI; CU=Cusco; LO=Loreto; UC=Ucayali.
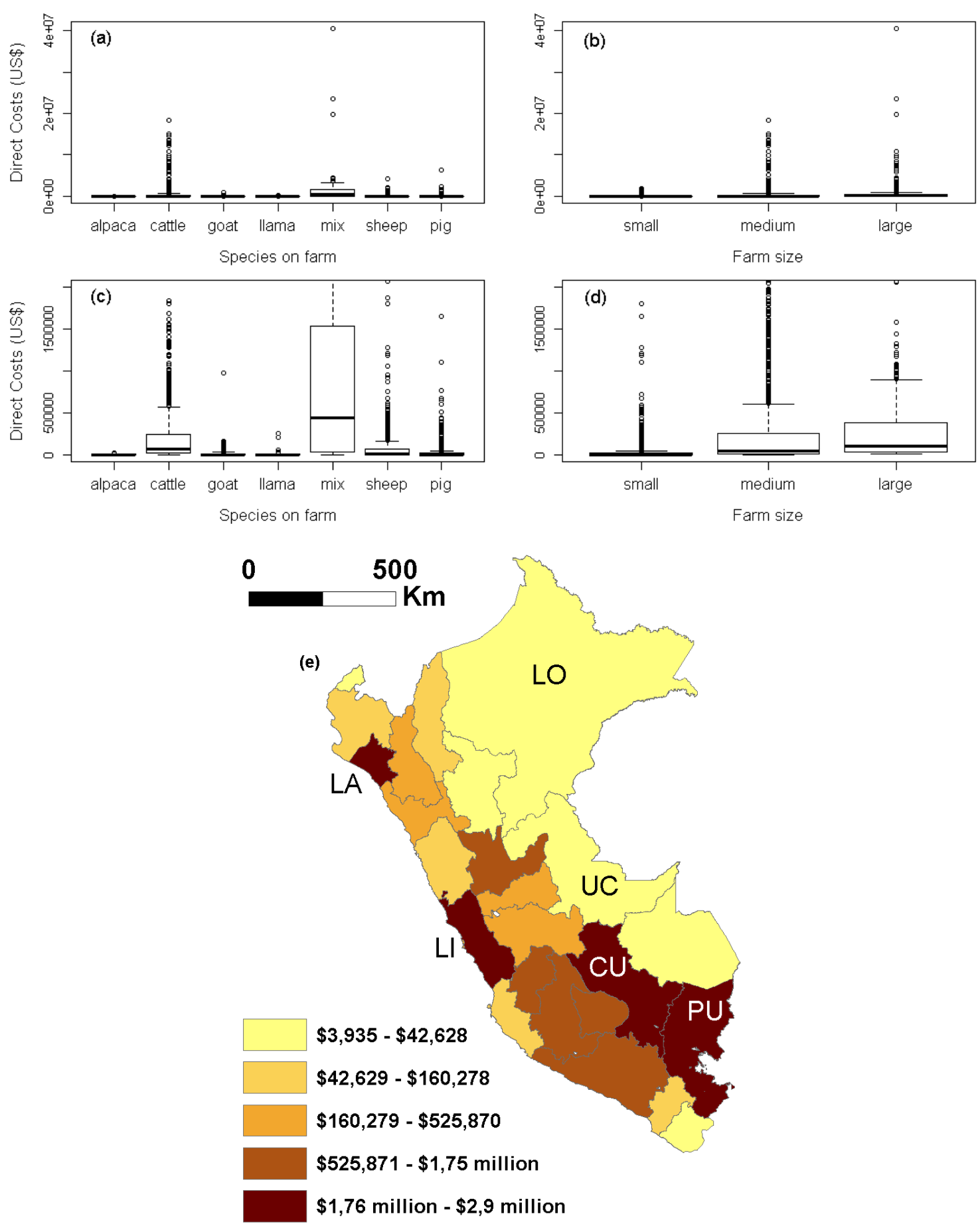
Figure 9. Comparison between the estimated overall risk map of the potential FMD spread in Peru (background color map) and the historical FMD outbreaks occurring in Peru from 1993 to 2004 (overlapped black dots, adapted from Valderrama et al., 2010)

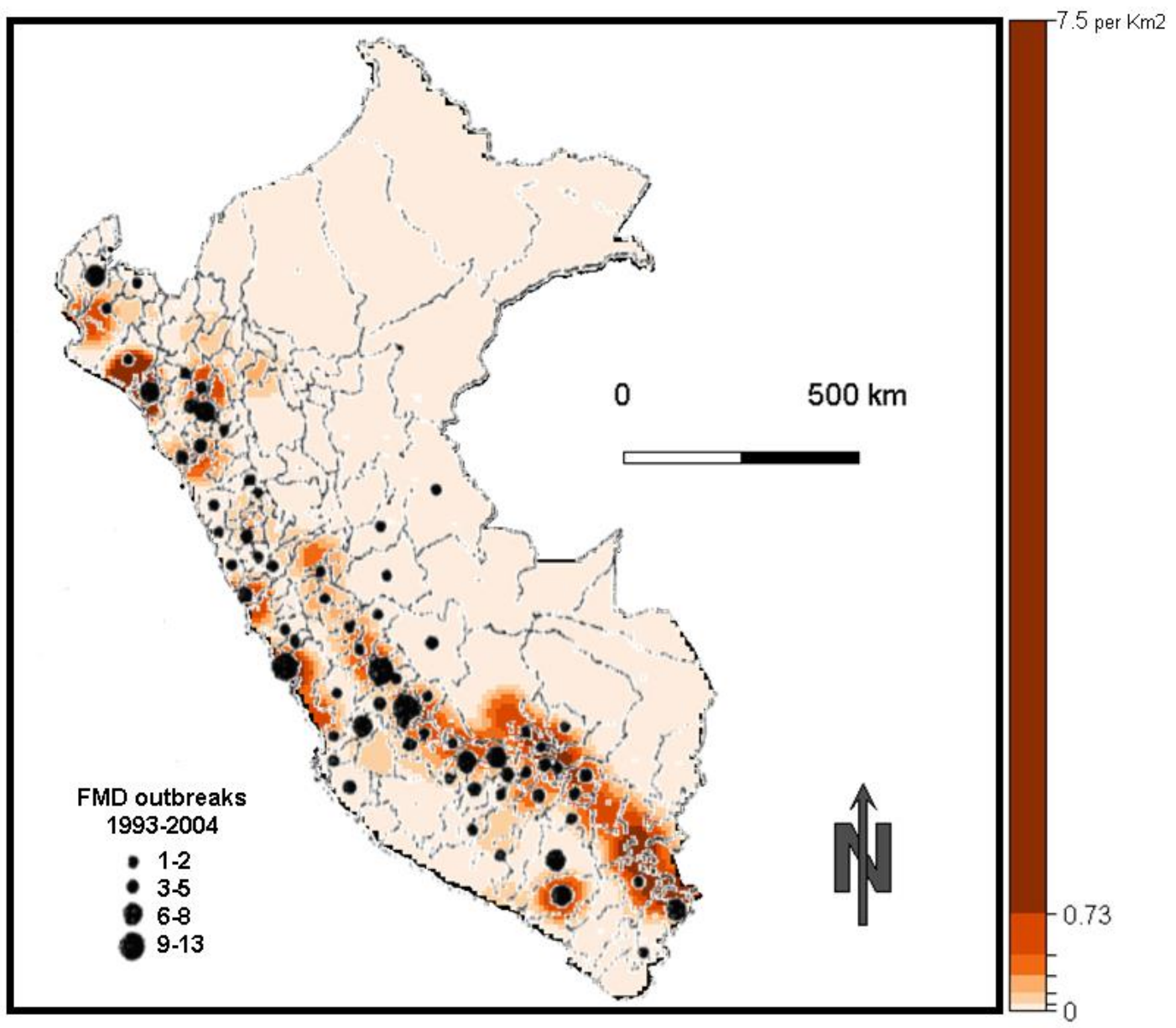


Figure 10. Comparison between the historical number of affected farms in Peru from 1983 to 2004 (adapted from Valderrama et al., 2010) and the mean estimated number of FMD infected farms in Peru using the Be-FAST model in the scenario with random selection of the index farm (sce1), random index farm among those with outgoing shipments (out-degree $>0$ ) (sce2), random index farm among those located in coast or mountain (sce3), random index farm among those located in the North of Peru (sce4) and when considering the total number of simulations (total). Red line depicts the mean of the historical number of outbreaks from 1983 to 2004.

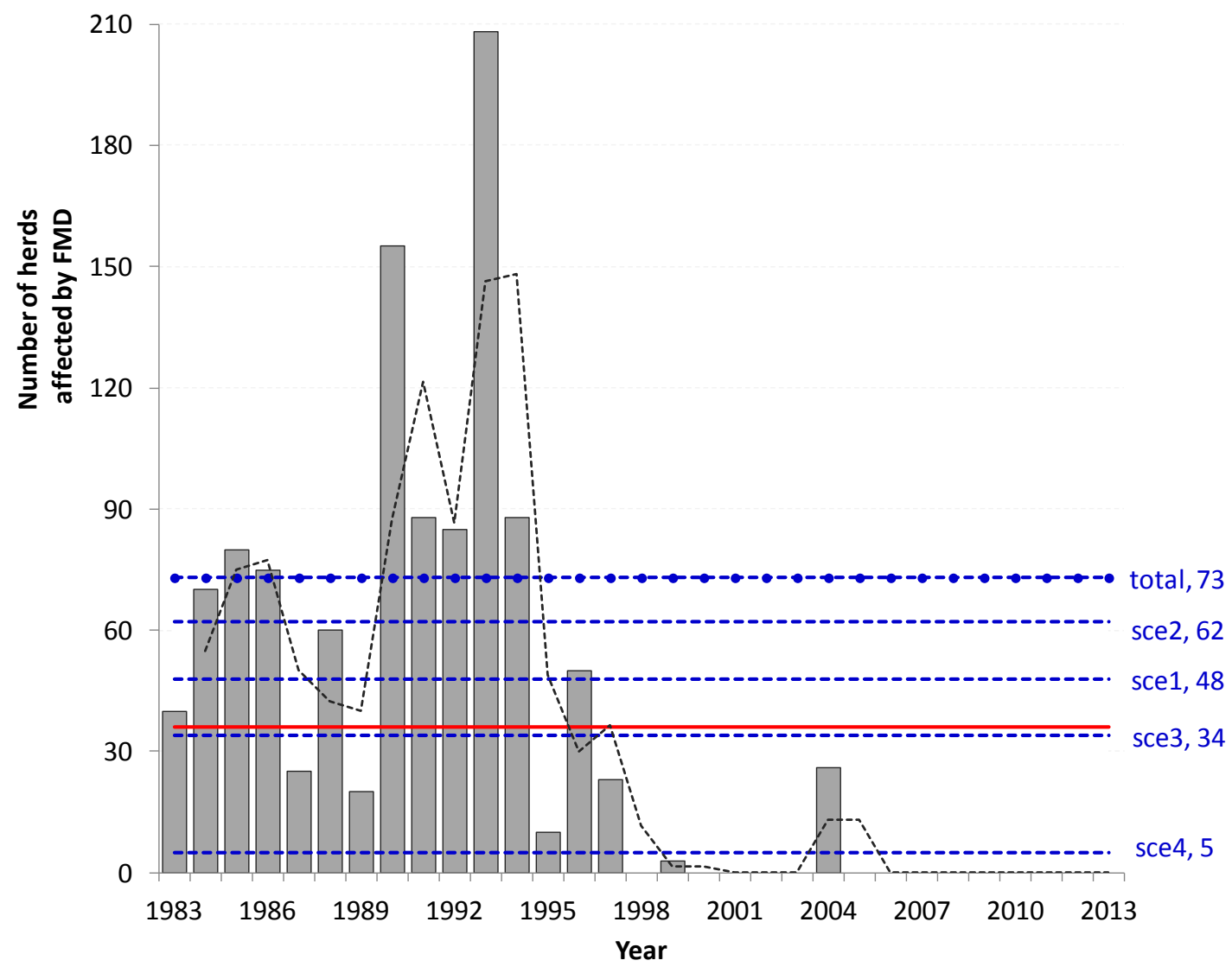

